\title{
Thickness and surface-properties of different sea-ice regimes within the Arctic Trans Polar Drift: Data from summers 2001, 2004 and 2007
}

\author{
L. Rabenstein, ${ }^{1,2}$ S. Hendricks, ${ }^{1}$ T. Martin, ${ }^{3}$ A. Pfaffhuber, ${ }^{4}$ and C. Haas $^{5}$ \\ Received 25 September 2009; revised 9 April 2010; accepted 21 September 2010; published 22 December 2010.
}

[1] Large-scale sea-ice thickness and surface property data were obtained in three summers and in three different sea-ice regimes in the Arctic Trans-Polar Drift (TPD) by means of helicopter electromagnetic sounding. Distribution functions $P$ of sea-ice thickness and of the height, spacing, and density of sails were analyzed to characterize ice regimes of different ages and deformations. Results suggest that modal ice thickness is affected by the age of a sea-ice regime and that the degree of deformation is represented by the shape of $P$. Mean thickness changes with both age and deformation. Standard error calculations showed that representative mean and modal thickness could be obtained with transect lengths of $15 \mathrm{~km}$ and $50 \mathrm{~km}$, respectively, in less deformed ice regimes such as those around the North Pole. In heavier deformed ice regimes closer to Greenland, $100 \mathrm{~km}$ transects were necessary for mean thickness determination and a representative modal thickness could not be obtained at all. Mean sail height did not differ between ice regimes, whereas sail density increased with the degree of deformation. Furthermore, the fraction of level ice, open melt ponds, and open water along the transects were determined. Although overall ice thickness in the central TPD was 50\% thinner in 2007 than in 2001, first-year ice (FYI) was not significantly thinner in 2007 than FYI in 2001, with a decrease of only $0.3 \mathrm{~m}$. Thinner FYI in 2007 only occurred close to the sea-ice edge, where open water covered more than $10 \%$ of the surface. Melt pond coverage retrieved from laser measurements was $15 \%$ in both the 2004 MYI regime and the 2007 FYI regime.

Citation: Rabenstein, L., S. Hendricks, T. Martin, A. Pfaffhuber, and C. Haas (2010), Thickness and surface-properties of different sea-ice regimes within the Arctic Trans Polar Drift: Data from summers 2001, 2004 and 2007, J. Geophys. Res., 115, C12059, doi:10.1029/2009JC005846.

\section{Introduction}

[2] Sea-ice thickness is an important parameter with a great influence on climatic processes in the Arctic [Holland et al., 2006]. Only two of the climate models mentioned in the fourth assessment report of the Intergovernmental Panel on Climate Change (IPCC) incorporate high-resolution seaice thickness distributions [McLaren et al., 2006; Meehl et al., 2006]. These two best predicted the decline in Arctic sea-ice extent [Stroeve et al., 2007]. Satellite observations of the aerial extent and concentration of Arctic sea ice have been available on a regular basis since 1979. They reveal strong

\footnotetext{
${ }^{1}$ Alfred Wegener Institute for Polar and Marine Research, Bremerhaven, Germany.

${ }^{2}$ Now at Swiss Federal Institute of Technology, Institute of Geophysics, Zürich, Switzerland.

${ }^{3}$ Leibniz Institute of Marine Sciences, IFM-GEOMAR, Kiel, Germany.

${ }^{4}$ Norwegian Geotechnical Institute, Oslo, Norway.

${ }^{5}$ Department of Earth Sciences, University of Alberta, Edmonton, Alberta, Canada.

Copyright 2010 by the American Geophysical Union. 0148-0227/10/2009JC005846
}

interannual variability of the sea-ice extent, which is superimposed by a decreasing trend of $3.7 \%$ per decade for all seasons since the beginning of the record until 2006 [Parkinson and Cavalieri, 2008]. The decrease even accelerated within the past decade to $10.1 \%$ [Comiso et al., 2008] and was particularly pronounced during September 2007, when an abrupt decline in sea-ice extent to only $62 \%$ of the climatological average emerged. Despite this observed decrease in ice extent, a long-term decrease in sea-ice volume remains unclear. Although a negative trend of sea-ice volume within the 20th century is supported by several submarinebased upward-looking sonar (ULS) sea-ice draft measurements [e.g., Wadhams and Davis, 2000b; Tucker et al., 2001; Yu et al., 2004], with an average decrease of $33 \%$ from a peak in 1980 to a minimum in 2000 [Rothrock et al., 2008], other publications discuss a controversial decrease of sea-ice volume in the 20th century [e.g., Winsor, 2001; Gerdes and Koeberle, 2007]. Owing to the progress of satellite altimetry techniques since the beginning of the 21 st century, sea-ice thickness data are available on an Arctic-wide scale, indicating an increased loss of sea-ice volume. On the basis of "ICESat" laser altimetry data, Kwok et al. [2009] found a 
volume loss of Arctic sea ice of more than 40\% since 2005. As for the decrease of sea-ice extent, this decrease was especially pronounced in 2007, which is also supported by the results of Giles et al. [2008] for the western Arctic, who obtained sea-ice thickness on the basis of satellite radar altimetry. In addition to remote sensing studies of sea-ice volume, a number of in situ sea-ice thickness data sets were collected by means of helicopter electromagnetics (HEM) in the Arctic Trans-Polar Drift (TPD) between 2001 and 2007. On the basis of HEM data, Haas et al. [2008] have shown a decrease of mean summer sea-ice thickness in the TPD from $2.2 \mathrm{~m}$ in 2001 to $1.3 \mathrm{~m}$ in 2007 , which is a decrease of $44 \%$. This dramatic thickness decline is mainly the consequence of a regime shift from multiyear to first-year ice in the TPD, which accompanied a significant reduction of perennial sea ice in the Arctic between March 2005 and March 2007 [Nghiem et al., 2007] and a trend toward an accelerated TPD [Rampal et al., 2009].

[3] The study presented here is based on partially the same HEM data sets as the study of Haas et al. [2008], namely, on HEM data taken in the TPD during the summers of 2001, 2004, and 2007. However, here we study the HEM data in more detail to investigate particular characteristics of sea-ice thickness and pressure ridge distributions and their relation to melt pond coverage and sea-ice concentration. In particular, we are interested in the shape of the distribution functions, the thickness and amount of undeformed ice, the amount of deformed ice, the dependence of thickness on the concentration of sea ice, and in latitudinal gradients within the distribution. Furthermore, in this study, we compare thickness and pressure ridge distribution functions with respect to the sea-ice regimes in which they were taken and with respect to their representativeness on the basis of standard errors. We discriminate between multiyear ice (MYI) and first-year ice (FYI) regimes [Haas et al., 2008] and between regimes with a mainly convergent ice drift north of Fram Strait or a mainly free ice drift in the region of the North Pole. Although we do not focus on the analysis of ice thickness trends in the TPD, which was the main goal of the previous study by Haas et al. [2008], our results are important for the understanding of sea-ice thickness changes in the Arctic. They provide details about the thickness distribution of seasonal ice in the record minimum year 2007 and compare them to the distribution functions of sea ice in the same region 6 years earlier. In addition, our study compares sea-ice thickness distributions north of Fram Strait with earlier ULS measurements by Wadhams and Davis [2000b].

[4] We follow the theory of sea-ice thickness distribution by Thorndike et al. [1975] and describe our results by calculating discrete probability density functions $P(z)$. Variations in $P(z)$ describe sea-ice conditions in different study areas and periods. An important parameter of the thickness distribution is the modal thickness, which is associated with local maxima in $P(z)$. It can be assumed that in FYI regimes, the modal thickness reflects vast areas of undeformed level sea ice which were formed at the same time during the autumn freezeup. Multiple modes give evidence for the presence of larger sea-ice areas in the survey area which were formed during different times. A mode of $P(z)$ located at $z=0$ represents open water. Owing to a longer melting and freezing period, undeformed sea ice in MYI regimes may not be considered as level any longer, such that a greater variety of undeformed ice thicknesses can be expected, i.e., $P(z)$ would be characterized by a broader mode.

[5] We performed a detailed level-ice study with the motivation to compare level-ice thickness and level-ice occurrence between the three expeditions into the Arctic Ocean during the three summers of 2001, 2004, and 2007. In particular, we examine whether 2007 FYI was significantly thinner than a small amount of FYI found in 2001 in the same region, as indicated by low ice extent and strong bottom melting reported in the Beaufort Sea [Perovich et al., 2008], or whether it differed within the range of natural variability. Level FYI thicknesses between two preceding summers may vary by as much as $0.3 \mathrm{~m}$ [Haas and Eicken, 2001]. To extract level ice in the data, a carefully tailored level ice filter was applied, which ensures that eroded pressure ridges are filtered out and do not contribute to the modal thicknesses.

[6] In addition, we calculated distribution functions of ridge-sail height, spacing, and density, which is the number of sails per kilometer. For this, we used surface roughness data measured with a laser altimeter which is incorporated in the HEM instrument, similarly to a study by Peterson et al. [2008]. A laser altimeter produces accurate measures of surface roughness after making corrections to account for variations in aircraft flight height. The technique is described in more detail in section 2.3. Ridge-draft and ridge-spacing distributions based on ULS data were intensively studied by Wadhams and Horne [1980], Bourke and Garrett [1987], and Davis and Wadhams [1996]. These studies found that ridge draft fits a negative exponential distribution and ridge spacing a lognormal distribution. Here we verify whether these findings can be applied to laser-derived sail heights and spacing.

[7] During the summer months, melting of sea ice creates melt ponds at the sea-ice surface. Melt ponds modify thickness distributions, as they result in enhanced local thinning due to their low albedo. Perovich et al. [2007], for instance, showed albedo values of 0.4 for a ponded surface at the beginning of August compared to 0.8 for a surface covered with dry snow. Haas and Eicken [2001] studied the influence of melt ponds on sea-ice thickness distributions and found that melt ponds are primarily located on the thinnest ice. Similarly to our study, Inoue et al. [2008] analyzed melt pond concentrations on sea ice of different ages in July 2003 in the Beaufort Sea and found typical concentrations of $25 \%$ on FYI and $30 \%$ on MYI. In this paper, we introduce a new method to estimate the amount of melt pond concentration by analyzing dropouts of the laser altimeter signal.

[8] Our 2007 HEM measurements are the only extensive thickness data obtained during the summer of 2007 and therefore represent a unique possibility to study the spatial and temporal changes of sea-ice thickness while the sea-ice extent was at its minimum. Steele et al. [2008] showed seasurface temperature anomalies for the Pacific side of the Arctic ocean of up to $5^{\circ} \mathrm{C}$ in 2007 . At the same time, Perovich et al. [2008] measured $2.1 \mathrm{~m}$ of bottom melt on an individual ice floe close to the sea-ice margin in the Beaufort Sea, which is more than six times the 1990s average. During the same period, bottom melting on an ice floe close to the North Pole was comparable to previous years [Perovich et al., 2008]. The difference between these two measurements suggests that the proximity to the sea-ice margin and the 
resulting lower sea-ice concentration accelerated the bottom melt. We analyze the 2007 thickness data with respect to enhanced thinning due to lower sea-ice concentrations and their relation to small distances to the sea-ice edge. We also compare our results to those of Perovich et al. [2008].

[9] Another focus of the present study is on the statistical reliability of the measurements. For the first time, we evaluate larger data sets of HEM sea-ice thickness to determine the significance of the obtained mean and modal thicknesses and mean pressure ridge sail parameters. Here an important quantity is the standard error $\epsilon$. The standard error is the standard deviation of an ensemble of mean or modal values obtained for transect subsections of the same lengths. When $\epsilon$ is calculated for section ensembles of different lengths, it is a measure of the transect lengths necessary to obtain mean and modal values which are representative of the entire data set. So, we answer the question as to how long HEM profiles should be to obtain reliable mean and modal thicknesses. Evaluation of standard errors for ULS submarine measurements was previously done by Wadhams [1997], who showed that for $50-\mathrm{km}$-long profiles obtained in essentially the same ice regime around the North Pole in a time window of 55 hours, the standard error of ice draft is about $12.75 \%$ of the mean thickness. Wadhams took this result as a reference standard error, which when exceeded indicates significant spatial or temporal variability.

\section{Data and Methods}

\subsection{Location and Period}

[10] The data sets presented here are from the three expeditions ARK17/2, ARK20/2, and ARK22/2 of the German research ice breaker $R / V$ Polarstern (Figure 1). ARK17 took place along the Gakkel Ridge and east of the North Pole in August-September 2001 [Thiede, 2002], ARK20/2 north of the Fram Strait in July-August 2004 [Budéus and Lemke, 2007], and ARK22/2 north of the Barents Sea and at the Pacific-Siberian side of the North Pole in August-September 2007 [Schauer, 2008]. The 2007 helicopter flight tracks were split into two regions because they were widely separated and were surveyed 3 weeks apart (Table 1). HEM sea-ice thickness surveys were performed along the cruise track as often as weather conditions allowed. Flight tracks were arranged along triangles (see Figure 1) with side lengths between $18.5 \mathrm{~km}$ (2001), $35 \mathrm{~km}$ (2004), and $70 \mathrm{~km}$ (2007). The increasing lengths of flights over the years demonstrates the operational advance in doing these measurements. Total survey lengths are listed in Table 1.

\subsection{Helicopter-borne Electromagnetic Sounding}

[11] HEM was pioneered in the 1950 s to detect ore deposits and was first applied over sea ice by Kovacs and Holladay [1990]. Since then, the method has been frequently used for sea-ice thickness determinations in the Arctic [e.g., Prinsenberg et al., 2002; Haas et al., 2006; Peterson et al., 2008; Haas et al., 2008]. Detailed information about the HEM instrument for measuring sea-ice thickness was already given by Haas et al. [2009], hence we only briefly summarize the HEM method here. A pair of transmitter and receiver coils operating at $4 \mathrm{kHz}$ are used to estimate the distance of the instrument to the ice-ocean interface. The dominant EM induction process takes place in the conductive seawater
[Pfaffling et al., 2007]. In addition, a laser altimeter yields the distance to the uppermost snow surface, hence snow plus ice thickness is obtained by the difference of laser and EM distance measurements. During all three expeditions, no snow cover was observed in August and on average $10 \mathrm{~cm}$ of new snow accumulated in September, which is in agreement with climatological snow depth data reported by Warren et al. [1999]. Snow depth was measured during several ground surveys on the ice and observed during continuous observations from the bridge of $R / V$ Polarstern [Thiede, 2002; Budéus and Lemke, 2007; Schauer, 2008]. Significant formation of drift banks could not be observed on the fresh snow cover. However, we cannot exclude the possibility that single samples of sea-ice thickness are biased by more than $10 \mathrm{~cm}$, owing to local snow accumulations.

[12] Compared to other HEM "birds" typically used in mineral exploration and geological mapping, the EM bird used here is small and easy to handle from the helicopter deck of a research vessel. The EM-derived distance is sampled at $10 \mathrm{~Hz}$, which yields an average point spacing of $4 \mathrm{~m}$ with a typical helicopter speed of $40 \mathrm{~m} / \mathrm{s}$. The laser altimeter beam has a wavelength of $905 \mathrm{~nm}$ and is sampled at $100 \mathrm{~Hz}$, which results in a point spacing of $0.4 \mathrm{~m}$. Owing to the diffusive nature of the EM induction process, every thickness sample has a certain footprint over which the ice thickness is averaged [Kovacs et al., 1995; Reid et al., 2006]. In this case, it is approximately 3.7 times the flight height of $10-15 \mathrm{~m}$ and leads to an underestimation of the maximum thickness of ridged ice by as much as $50 \%$; open water spots smaller than the footprint cannot be detected at all. Furthermore, 3-D numerical modeling studies have shown that over long profiles of deformed ice, the true mean thickness and the HEM mean thickness are in good agreement [Hendricks, 2009], and validation experiments have shown that determination of modal thickness is achieved with an accuracy of $0.1 \mathrm{~m}$ [Pfaffling and Reid, 2009]. As a consequence of the instrument error, ice thickness samples thinner than $0.1 \mathrm{~m}$ are considered open water.

\subsection{Laser Profiling of Pressure Ridge Sails and Melt Ponds}

[13] Using a nadir looking $100 \mathrm{~Hz}$ laser altimeter, we measured ridge-sail heights and spacing along the HEM profile. For ridge detection, a combination of low- and highpass filters was applied to the laser data to remove signals due to altitude variations of the helicopter [Hibler, 1972]. Local maxima in the filtered laser signal are inferred to represent pressure-ridge sails if they exceed a cutoff height of $0.8 \mathrm{~m}$ above the local level-ice height. In addition, two adjacent sails have to fulfill the Rayleigh criterion, i.e., they have to be separated by a data point of more than half their height to be considered as separate features.

[14] Furthermore, we identify dropouts in the laser signal to estimate the fraction along the HEM transect, which was covered with open melt ponds. Over snow and ice, a diffusive laser reflection can be expected, whereas a specular return or an absorption of the laser energy in the water column occurs over open water [Hoefle et al., 2009]. Hence laser dropouts may occur over open water and melt ponds due to absorption or when specular reflections are missed by the laser altimeter owing to small pitch and roll movements of the bird. Since the sample frequency of the laser is $100 \mathrm{~Hz}$ 


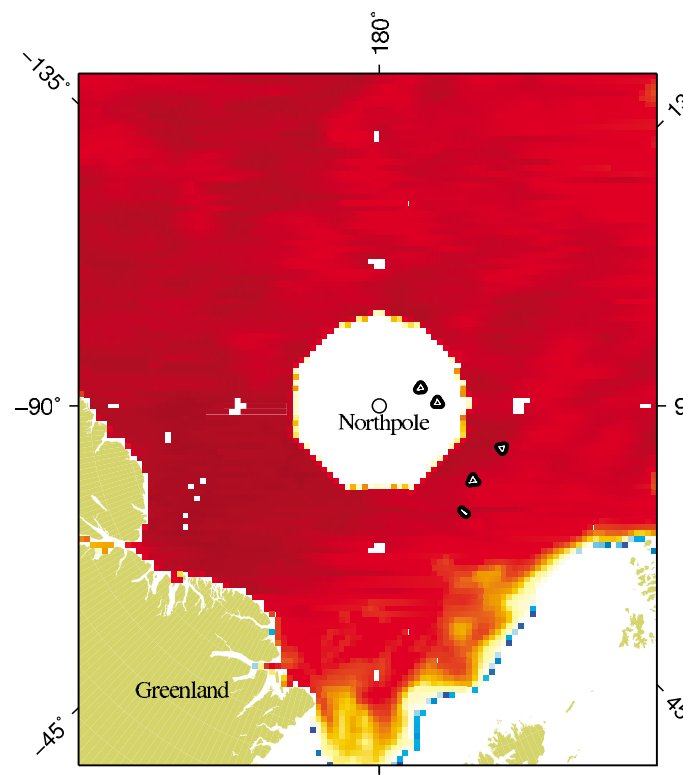

a) ARK17/2 - 09-2001

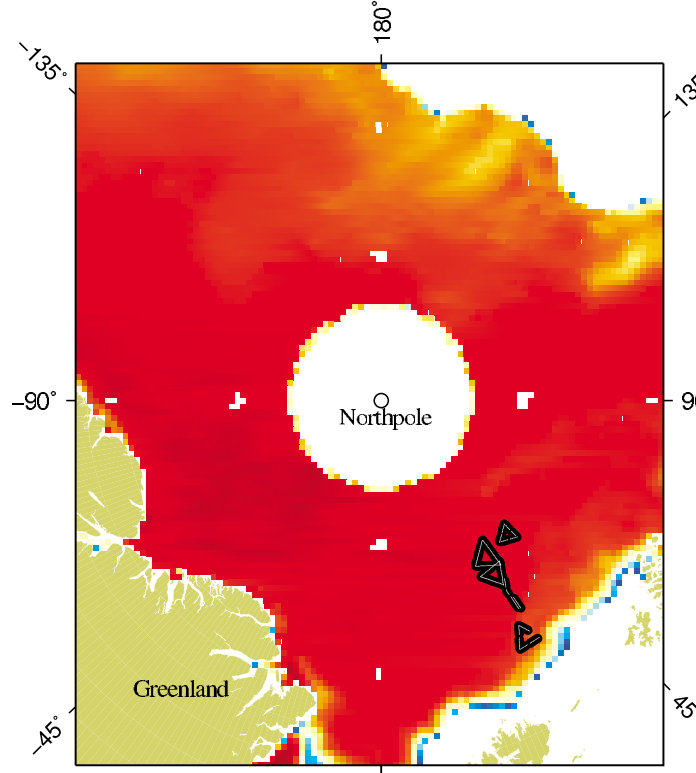

c) ARK22/2 - 08-2007

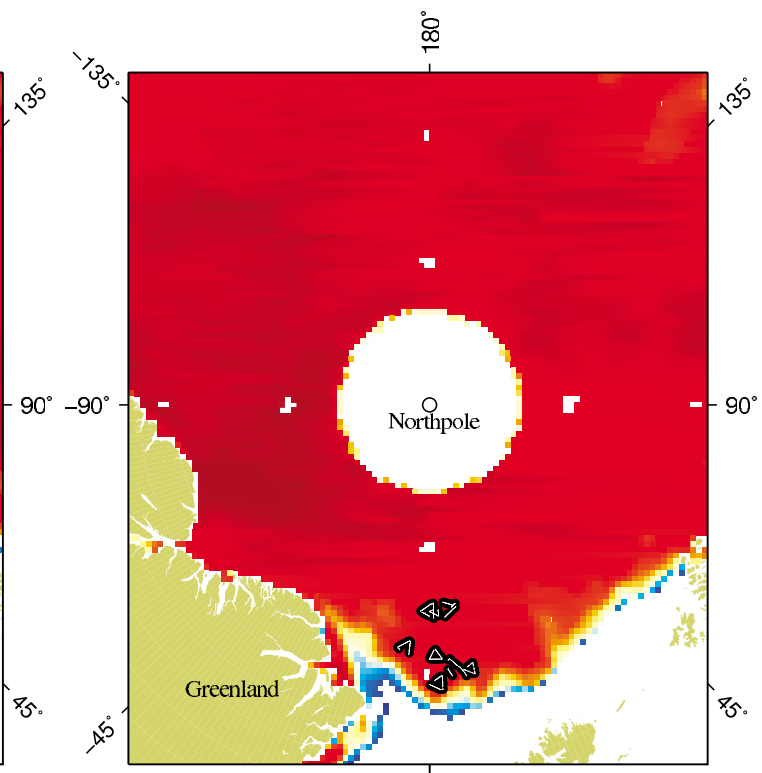

b) ARK20/2 - 08-2004

$\stackrel{\circ}{\circ}$

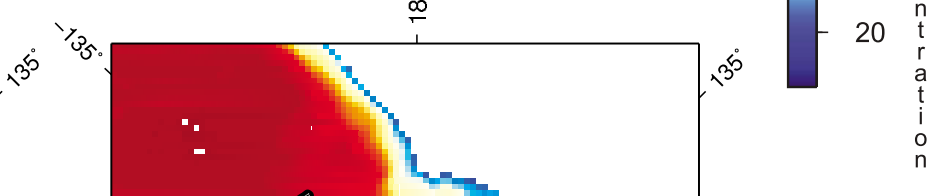

Figure 1. Maps of all HEM flights and respective SSM/I sea-ice concentration during each campaign.

Table 1. Parameters of the HEM Surveys and Results of the Thickness Measurements ${ }^{\mathrm{a}}$

\begin{tabular}{|c|c|c|c|c|c|c|c|c|c|c|}
\hline Year & $\begin{array}{l}\text { Time Period } \\
\text { (dd.mm) }\end{array}$ & Region & $\begin{array}{l}\text { Total } \\
\text { Length } \\
(\mathrm{km})\end{array}$ & $\begin{array}{l}\text { Overall Mean } \\
\text { Thickness } \\
\text { (m) }\end{array}$ & $\begin{array}{l}\text { Overall Modal } \\
\text { Thickness } \\
(\mathrm{m})\end{array}$ & $\begin{array}{c}\text { FWHM } \\
(\mathrm{m})\end{array}$ & $\begin{array}{l}\text { Open Water } \\
\text { Content } \\
(\%)\end{array}$ & $\begin{array}{l}\text { Level Ice } \\
\text { Content } \\
(\%)\end{array}$ & Curvature $B$ & $\begin{array}{c}\text { Open Melt } \\
\text { Ponds } \\
(\%)\end{array}$ \\
\hline 2001 & $30.08-20.09$ & $\begin{array}{l}\text { Gakkel Ridge \& East } \\
\text { of North Pole }\end{array}$ & 260 & $2.28 \pm 0.95$ & 2.0 & 0.7 & 4 & 16 & 1.28 & 1 \\
\hline 2004 & $23.07-14.08$ & North of Fram Strait & 812 & $2.63 \pm 1.32$ & 2.1 & 1.3 & 1.8 & 9.5 & 0.86 & 15 \\
\hline $2007 \mathrm{a}$ & $03.08-10.08$ & North of Barents Sea & 931 & $1.36 \pm 0.73$ & 0.9 & 0.8 & 0.5 & 20.5 & 1.47 & 15 \\
\hline $2007 b$ & $28.08-18.09$ & $\begin{array}{l}\text { Northpole toward } \\
\text { Pacific/Siberia }\end{array}$ & 3180 & $1.22 \pm 0.79$ & 0.9 & 0.8 & 5.4 & 19.1 & 1.44 & 0 \\
\hline
\end{tabular}

${ }^{\mathrm{a}} \mathrm{FWHM}$ is the full-width-half-maximum of the thickness distribution function. Open water content is the percentage of ice thinner than $0.1 \mathrm{~m}$. Level-ice content is calculated with an adapted level-ice filter (see section 3.5). Curvature B describes the tail of the thickness distribution function. Open melt ponds are determined using the algorithm as explained in section 3.4. 


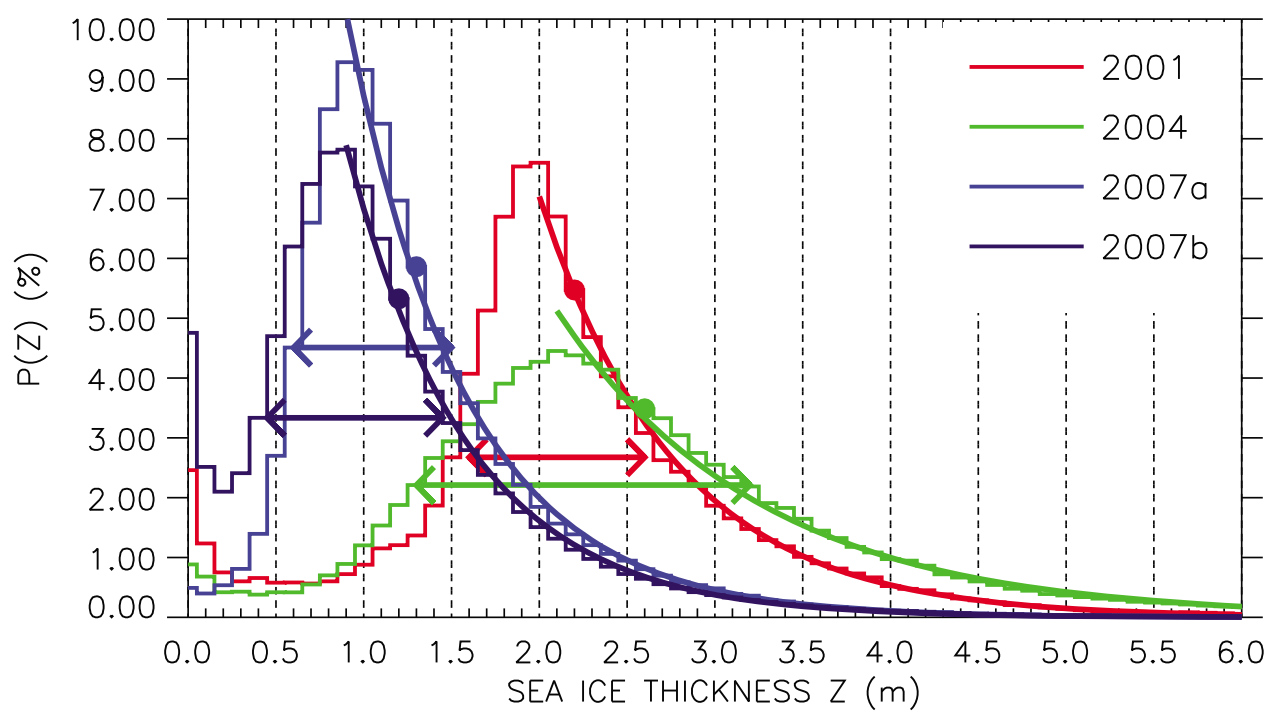

Figure 2. Overall sea-ice thickness distributions including open water. Circles mark the mean ice thickness, and arrows indicate the full width at half maximum (FWHM). Exponential fits for the tails of the distributions are plotted as solid lines.

and that of the EM signal is $10 \mathrm{~Hz}, 10$ laser samples are merged with one EM sample. When at least 1 of these 10 samples is a dropout, and when ice thickness is larger than $0.1 \mathrm{~m}$, we classify the particular thickness sample as a melt pond measurement. This classification may fail where open leads and thaw holes are much smaller than the footprint of the EM bird, as this may result in thickness values of more than $0.1 \mathrm{~m}$. In such cases, open water spots and melt ponds cannot be distinguished. Although the accuracy of the absolute melt pond concentration is uncertain, owing to a lack of validating data, we show relative changes between the years. Over melt ponds, extensive drill hole studies showed that EM-derived ice thicknesses agree with the ice plus meltwater thickness within $0.1 \mathrm{~m}$ as long as melt pond salinities are low [Haas et al., 1997; Eicken et al., 2001].

\section{Results and Discussion}

\subsection{General Sea Ice Conditions}

[15] As shown by Haas et al. [2008], all data from 2001 and 2004 were collected over predominantly multiyear ice (MYI) and all 2007 data were collected over predominantly FYI. Most data were recorded in regions with high ice concentrations of $>90 \%$, except those profiles located close to the Siberian-Pacific sea-ice margin in September 2007 (Figure 1d). Ice concentrations shown in Figure 1 are negatively biased by melt ponds in a way described by Inoue et al. [2008]. Not visible in Figure 1 are leads around the North Pole in 2001, which led to measured open water content for individual flights of up to $15 \%$ [Thiede, 2002]. The profiles flown in August 2007 (Figure 1c) were originally intended to extend farther north, but the $R / V$ Polarstern had difficulties breaking through the ice even though mean thickness was below $1.4 \mathrm{~m}$ (Table 1). By contrast, in September 2007, $R / V$ Polarstern steamed without any difficulties through ice which was on average only $15 \mathrm{~cm}$ thinner. Additional details of the four data sets are given in Table 1.

\subsection{Thickness Distribution}

[16] The thickness distributions $P(z)$ of the 2001, 2004, and 2007 HEM surveys, together with their means, exponential decays, and full width at half maximum (FWHM) values, are shown in Figure 2. FWHM is the width of $P(z)$, where it is at $50 \%$ of the maximum. For all four data sets, the distribution was asymmetric, with most of the ice distributed in the thicker part. None of the four distributions showed more than a single maximum, open water, i.e., the maximum at $z=0$, not included. Typical sea-ice sections for each data set are shown in Figure 3.

[17] Although 2001 was dominated by MYI and 2007 by FYI, both distribution functions were surprisingly similar in shape, as demonstrated by the similar FWHM (Table 1). This is an indicator for a common dynamic history of both sea-ice regimes, since according to Thorndike et al. [1975], only dynamic components are responsible for a redistribution of thinner ice toward thicker ice and therefore for a broadening of $P(z)$. The larger FWHM of the 2004 data indicates either a larger degree of deformation in the ice cover or the presence of several ice thickness classes with different histories. Both explanations are typical for a MYI cover in the region north of Fram Strait, where sea ice from all over the Arctic Ocean converges, owing to a constriction by the land masses of Greenland and Svalbard. This convergent ice regime includes sea ice from, e.g., North of Greenland which probably remained there for multiple years but also younger MYI which advects from the central Arctic Ocean.

[18] The most prominent difference between the years was the position of the maxima of $P(z)$, which represents the modal thickness. Modal thickness differed by as much as $1.2 \mathrm{~m}$ between the thinner maxima of $0.9 \mathrm{~m}$ in 2007 and the thicker ones of $2.0 \mathrm{~m}$ and $2.1 \mathrm{~m}$ in 2001 and 2004 . This reduction was a consequence of the disappearance of MYI from this part of the Arctic Ocean in 2007 [Nghiem et al., 2007]. The mean thickness also decreased from $2.3 \mathrm{~m}$ in 2001 to $1.3 \mathrm{~m}$ in 2007. The 2004 mean thickness was particularly large, differing from the 2001 mean thickness 

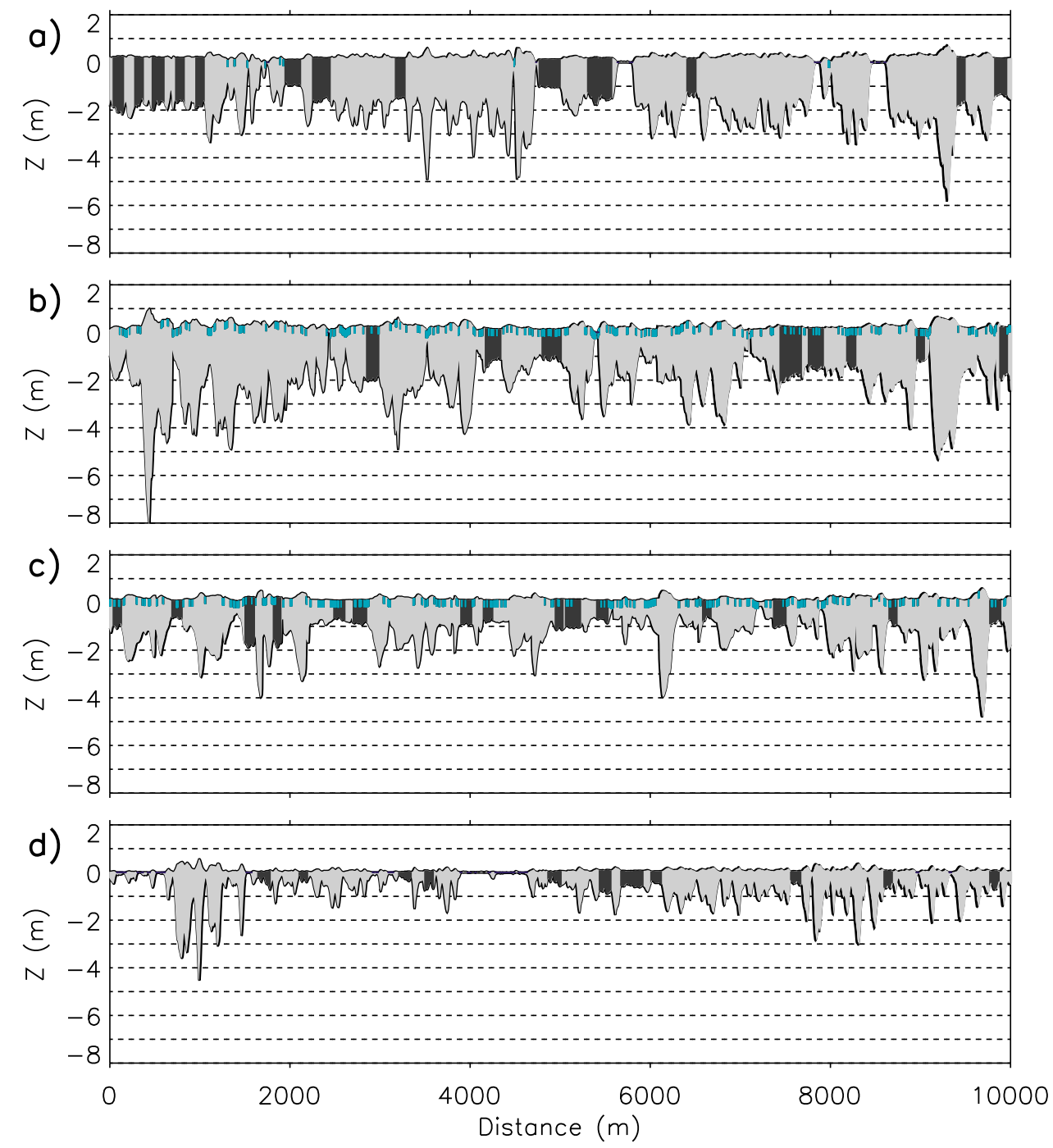

Figure 3. 10-km-long sea-ice sections representing typical profiles obtained during each campaign, where $Z=0$ marks the sea level. A freeboard to draft ratio of 0.89 was assumed to convert ice thickness into freeboard and draft. Dark sea-ice sections mark level ice as identified with the level-ice filter. Blue bars at the sea-ice surface are melt ponds located by laser dropouts. Most of the larger ridges are melt pond-free. (a) 3 September $2001,86.5^{\circ} \mathrm{N} / 72^{\circ} \mathrm{E}$. Level-ice sections at $2 \mathrm{~km}$ and $5 \mathrm{~km}$ are first-year ice. (b) 3 August $2004,83.4^{\circ} \mathrm{N} / 4.7^{\circ} \mathrm{W}$. Melt ponds are present and level-ice thickness ranges from 1-2 m. (c) 3 August $2007,82.8^{\circ} \mathrm{N} / 31^{\circ} \mathrm{E}$. Melt ponds are present. (d) 17 September $2007,82.2^{\circ} \mathrm{N} / 109^{\circ} \mathrm{E}$. This section was obtained at the marginal sea ice zone.

by $0.35 \mathrm{~m}$, although the modal thickness was similar. This indicates similar thermal but different dynamic histories of the two MYI regimes. The reduction of mean and modal thickness in the central Arctic Ocean within the past 16 years was further studied by Haas [2004] and Haas et al. [2008], who used data ranging back to 1991, including the data presented here. They found a decrease of mean thickness in the central Arctic of 58\% between 1991 and 2007.

[19] As for sea-ice draft distributions from ULS data [Wadhams and Davy, 1986], the tail of the thickness distribution $P_{r d g}(z)$ can be fitted by a negative exponential function (Figure 2)

$$
P_{r d g}(z)=A e^{-B\left(z-z_{m o d}\right)}
$$

where $z_{\text {mod }}$ is the modal sea-ice thickness, $z$ is the sea-ice thickness, and $A$ and $B$ are two fitting parameters. The curvature $B$ is the inverse of the standard deviation of the mean sea-ice thickness. The lower the curvature of $B$, the higher the amount of thicker deformed ice. Accordingly, $B$ indicates there was a higher amount of deformed ice in the MYI cover of 2001 than in the FYI cover of 2007, and the degree of deformation of the MYI cover of 2004 was considerably higher than that of both 2001 and 2007. All $B$ values are listed in Table 1. A direct comparison of our curvatures with B values obtained from ULS measurements is difficult, since B is influenced by the different footprint averaging of HEM systems and ULS systems; the HEM method may underestimate the thickness of pressure ridges by up to $50 \%$. 
[20] To summarize, we can state that the 2007 FYI and the 2001 MYI distributions are similar in shape but not in mean and modal thickness, for which 2001 showed a higher agreement with the 2004 MYI. The most plausible explanation is that 2001 MYI and 2007 FYI experienced similar dynamic but different thermodynamic histories, namely, different ice-growth periods. The opposite is true for 2001 and 2004 MYI, where similar modal thicknesses were produced thermodynamically, but both regimes were subject to different dynamics in that the 2004 regime was subject to heavier deformation, owing to the location in a convergent drift regime north of Fram Strait.

[21] As a further conclusion, we hypothesize that the tail of thickness distributions $P_{r d g}(z)$ and the FWHM value do not necessarily increase with age, as shown by the comparison between 2001 MYI and 2007 FYI. The transition into a convergent stage has a stronger effect on both parameters as demonstrated by the 2004 data. However, the connection of curvature $B$ and the amount of deformed ice in 2004 could be biased by the broad FWHM. In other words, we can think of the $2004 P(z)$ as a superposition of several $P(z)$ from different ice regimes, each with a slightly different mode. Each ice thickness mode has an associated tail due to deformed ice, and therefore modes might be influenced by tails. Moreover, we conclude that in a MYI regime, only the FYI mode would be distinctly separated from the dominant one. A mode related to sea ice older than 2 years simply increases the FWHM, as the 2004 thickness distribution implies. $P(0)$ determines the amount of open water with only 2001 with $4 \%$ and $2007 \mathrm{~b}$ with $5.4 \%$ showing a significant amount.

[22] Compared to earlier ULS measurements of late summer sea-ice thickness between Fram Strait and the North Pole [Wadhams and Davis, 2000b], the 2004 mean sea-ice thickness between $82^{\circ} \mathrm{N}$ and $85^{\circ} \mathrm{N}$ is $60 \%$ thinner than in 1976 and $22 \%$ thinner than in 1996.

\subsection{Ridge Distribution}

[23] Even when modal thickness is a good indicator for distinguishing between FYI and MYI, pressure ridge parameters are not. The mean height of pressure ridge sails differed by a maximum of only $0.13 \mathrm{~m}$ in all regimes and therefore cannot be taken as a reference, either for the age or for the modal or mean ice thickness of a regime. However, all data are based on summer measurements; in winter, the conditions may be different owing to an absence of surface melting. Nevertheless, pressure ridge sail distributions provide information about the degree of deformation within a sea-ice regime. Intuitively, we expect higher sails, a higher sail density, and a smaller spacing between the sails in a more deformed ice regime, such as in the 2004 survey area north of Fram Strait, where we observed the highest mean sail height and the highest mean sail density or lowest mean sail spacing, respectively. The histograms and the fitted distribution functions of the three sail parameters are shown in Figure 4. Further statistical ridge parameters are listed in Table 2.

[24] Of the three ridge parameters, sail height $h$ differs least between the three different ice regimes. For instance, in the 2001 MYI regime with a modal thickness of $2.0 \mathrm{~m}$, mean sail height was just $0.04 \mathrm{~m}$ or $10 \%$ higher than in the 2007a FYI regime with a modal thickness of $0.9 \mathrm{~m}$. As for the tail of the thickness distribution, the distribution of sail heights can be described by a negative exponential fit for all data sets (Figure 4a). The fitting function is

$$
P_{\text {sail }}(h)=C e^{-D\left(h-h_{\text {cut }}\right)}
$$

where $C$ and $D$ are the fitting parameters and $h_{c u t}$ is the cutoff height of $0.8 \mathrm{~m}$. The curvature $D$ of the distribution and mean sail height plus its standard deviation for every year are shown in Table 2. The correlation $r$ between fitted and calculated sail height distributions is higher than 0.99 for all years.

[25] The spacing $s$ and density $d$ of pressure ridges can be approximated by a lognormal distribution [Wadhams and Davy, 1986]

$$
P(x)=\frac{1}{\sqrt{2 \pi} \sigma(x+\theta)} e^{-\frac{(\ln (x+\theta)-\mu)^{2}}{2 \sigma^{2}}}
$$

where $\mu, \sigma$, and $\theta$ are the fitting parameters and $x$ represents $s$ or $d$, respectively. The maximum of $P(x)$ is at

$$
x_{\max }=\theta+e^{\left(\mu-\sigma^{2}\right)}
$$

and the mean is at

$$
x_{\text {mean }}=\theta+e^{\left(\mu+\frac{\sigma^{2}}{2}\right)} .
$$

The fitting parameters for $P(s)$ and $P(d)$ are listed in Tables 3 and 4. Mean spacing and density are directly related, whereas the modes differed significantly. Modal spacing in relation to mean spacing was 6 to $11 \mathrm{~m}$, almost equal for all data sets, but differences in modal density were 2 to 5 sails per kilometer in the same order of magnitude as differences in mean density. This is evidence that ridge sails tend to emerge in clusters, with a preferential spacing between 6 and $11 \mathrm{~m}$ within the cluster. Those clusters are probably associated with a single deformation zone in which the number of keels is not necessarily equal to the number of sails. Larger sail spacing in the distribution function can be assigned to level-ice areas which separate two deformation zones from each other. The correlations $r$ between the true distributions of $s$ and $d$ and the lognormal fits are higher than 0.9 and 0.99 , respectively, for all data except 2001, where they are 0.69 and 0.95 , respectively. The lower correlation for 2001 most probably results from the smaller number of samples and the consequently coarser distribution histogram, and not from the fact that the 2001 sail distribution follows a different functionality, which would be in contrast to previous publications [e.g., Davis and Wadhams, 1996; Wadhams, 2000a].

\subsection{Standard Errors}

[26] To quantify how representative the obtained results are, we calculate the standard error $\varepsilon$ of the modal and mean thickness as well as of the means of the examined ridge parameters [Wadhams, 1997]. The standard error $\varepsilon$ is given by

$$
\varepsilon_{\bar{Z}}(l)=\left\{\sum_{i=1}^{n}\left(\bar{Z}-Z_{i}\right)^{2} / n\right\}^{\frac{1}{2}}
$$


a.)

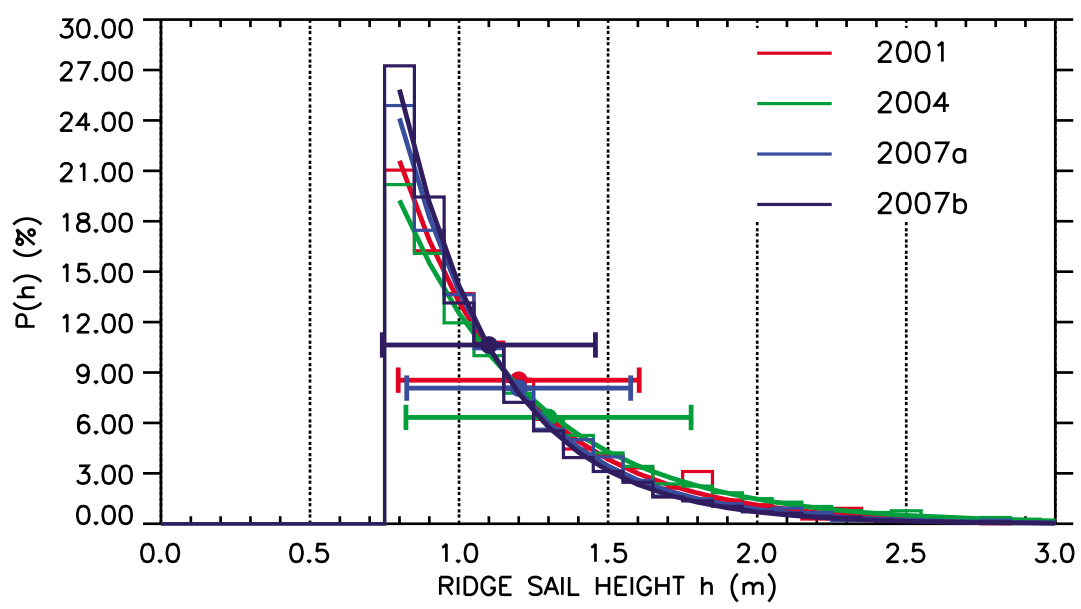

b.)

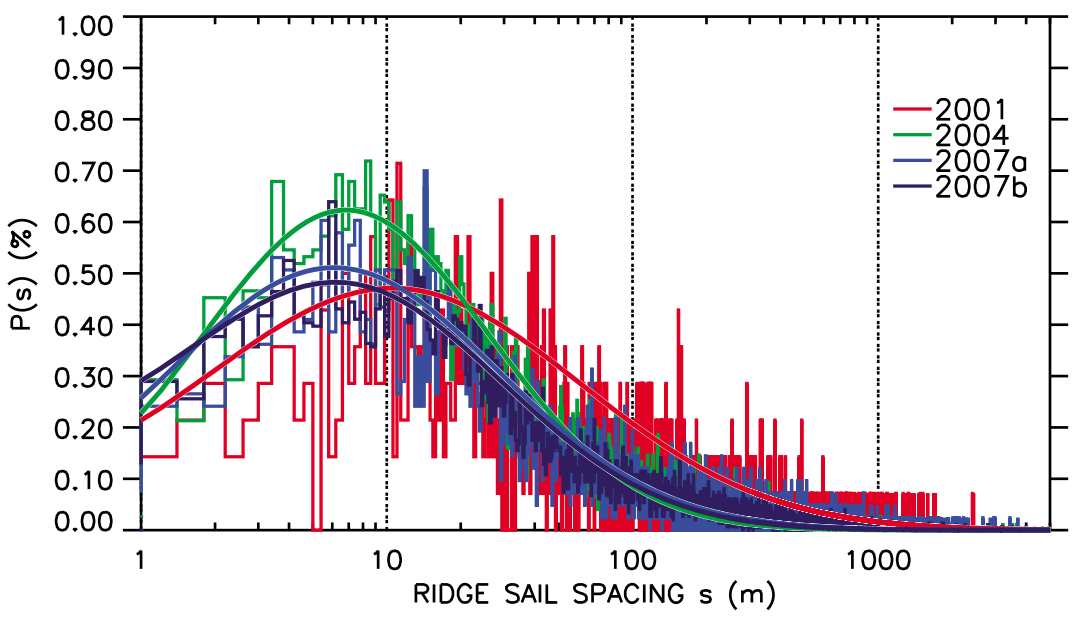

c.)

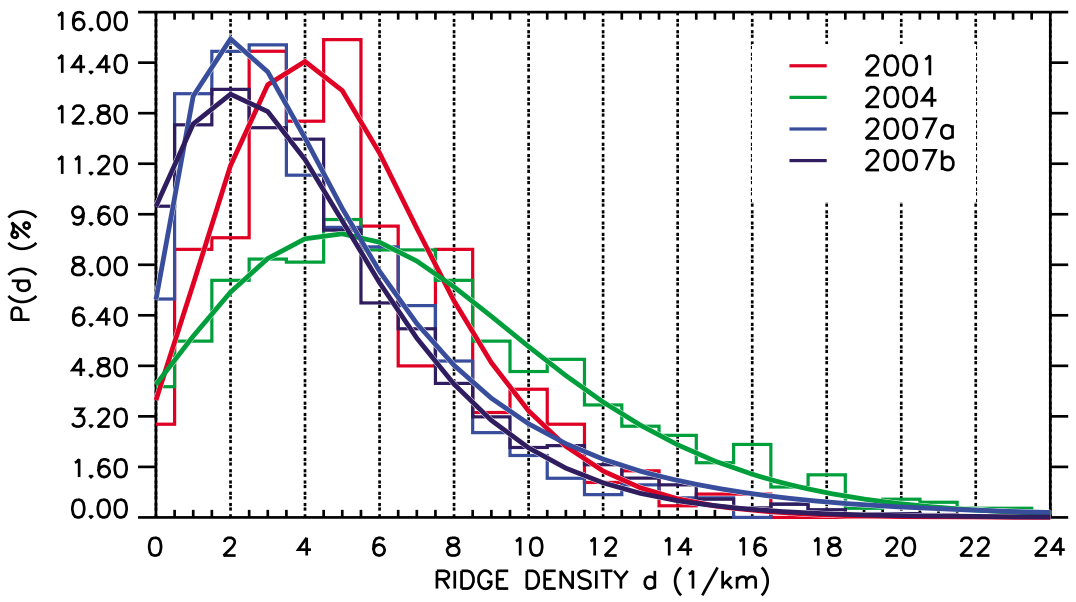

Figure 4. (a) Distribution of sail heights fitted with a negative exponential function. No sails lower than the cutoff height of $0.8 \mathrm{~m}$ are detected. (b) Histograms of sail spacing plotted with a bin width of $0.4 \mathrm{~m}$ together with the lognormal fits. (c) Histograms of sail density in sails per kilometer with a bin size of 1 together with the lognormal fits. 
Table 2. Ridge-Sail Parameters ${ }^{\mathrm{a}}$

\begin{tabular}{|c|c|c|c|c|c|c|c|c|c|}
\hline Year & $\begin{array}{l}\text { Mean Sail } \\
\text { Height }(\mathrm{m})\end{array}$ & $\begin{array}{c}\text { Max Sail } \\
\text { Height }(\mathrm{m})\end{array}$ & Curvature D & $\begin{array}{c}\text { Mean Sail } \\
\text { Spacing (m) }\end{array}$ & $\begin{array}{c}\text { Min/Max } \\
\text { Spacing }(\mathrm{m})\end{array}$ & $\begin{array}{c}\text { Modal Sail } \\
\text { Spacing (m) }\end{array}$ & $\begin{array}{c}\text { Mean Sail } \\
\text { Density }(1 / \mathrm{km})\end{array}$ & $\begin{array}{c}\text { Modal Sail } \\
\text { Density }(1 / \mathrm{km})\end{array}$ & $\begin{array}{c}\text { Min/Max } \\
\text { Density }(1 / \mathrm{km})\end{array}$ \\
\hline 2001 & $1.21 \pm 0.40$ & 4.61 & 2.47 & $193 \pm 254$ & $0.88 / 2433$ & 11 & $5.17 \pm 3.27$ & 3 and 5 & $0 / 16$ \\
\hline 2004 & $1.27 \pm 0.48$ & 4.90 & 2.15 & $139 \pm 230$ & $0.22 / 5662$ & 8 & $7.20 \pm 5.10$ & 5 & $0 / 40$ \\
\hline $2007 \mathrm{a}$ & $1.17 \pm 0.38$ & 4.36 & 2.75 & $233 \pm 322$ & $0.72 / 3686$ & 6 & $4.28 \pm 3.35$ & 2 & $0 / 23$ \\
\hline $2007 b$ & $1.14 \pm 0.36$ & 4.97 & 2.93 & $220 \pm 353$ & $0.64 / 5021$ & 6 & $4.50 \pm 3.83$ & 2 & $0 / 28$ \\
\hline
\end{tabular}

${ }^{a}$ Numbers following a \pm symbol are standard deviations of the particular quantity. $D$ is the curvature of the sail-height distribution.

where $\bar{Z}$ is the mean or mode of the complete data set, $Z_{i}$ is the mean or mode of the $i$ th subsection of the data set, $n$ is the number of subsections, and $l$ is the length of the particular subsection. Thus the standard error is the standard deviation of an ensemble of subsection means or modes where all subsections concatenate to form the complete data set. The standard error $\varepsilon$ is a function of the subsection length $l$, but also of the degree of homogeneity of the ice regime, expressed by, e.g., multiple modes in the distribution function or a large FWHM. As a consequence, different ice regimes require different section lengths to determine the overall mean or the overall mode with a certain statistical reliability. For the determination of $\varepsilon$, we subdivided the flights into smaller sections ranging from $50 \mathrm{~m}$ to the maximum flight length and even longer sections by concatenating all flights in a particular year. Results of all standard error determinations are shown in Figure 5.

[27] In the following, we denote $\varepsilon$ of the mean and the modal thickness by $\varepsilon_{\text {mean }}$ and $\varepsilon_{\text {mod }}$. For thickness determination, the error is limited to the maximum accuracy of the HEM bird of $\pm 0.1 \mathrm{~m}$, which represents a $0.2 \mathrm{~m}$ thickness interval. Therefore, we consider a measurement of mean or modal thickness as representative for a particular ice regime if $\varepsilon$ is equal to or below the interval of $0.2 \mathrm{~m}$. Previous thickness studies suggested an $\varepsilon_{\text {mean }}$ as a percentage of the overall mean thickness of $12.75 \%$ as the threshold for representativeness [Wadhams, 1997]. We tested for both criteria to evaluate our results. $\varepsilon_{\text {mean }}$ decreases steadily as $l$ increases and reaches the accuracy of $0.2 \mathrm{~m}$ at a length of $10 \mathrm{~km}$ in 2001, at $100 \mathrm{~km}$ in 2004, and at $15 \mathrm{~km}$ in 2007 (Figure 5a, left). All data sets fulfill the Wadhams [1997] requirement for representativeness at profile lengths of $5 \mathrm{~km}$ for 2001 , $30 \mathrm{~km}$ for 2004, and $100 \mathrm{~km}$ for 2007 (Figure 5b, left). However, we prefer the absolute standard error, since an error of, for instance, $0.2 \mathrm{~m}$ should have the same weight in thicker and thinner ice regimes. Furthermore, the comparison of absolute standard errors obtained in different thickness regimes is justified owing to the nondependency of the standard error on mean thickness [Wadhams, 1997; Percival et al., 2008]. All $\varepsilon_{\text {mean }}$ values are shown on the left side of Figures $5 \mathrm{a}-5 \mathrm{c}$. The decrease of $\varepsilon_{\text {mean }}$ with profile

Table 3. The Three Lognormal Fit Parameters for Sail Spacing, the Mean and Modal Sail Spacing, and the Correlation $r$ Between Fit and Measurements

\begin{tabular}{ccccccc}
\hline Year & $\sigma$ & $\mu$ & $\theta$ & $s_{\text {mean }}(\mathrm{m})$ & $s_{\max }(\mathrm{m})$ & $r$ \\
\hline 2001 & 1.93 & 6.09 & 0.19 & 1038.80 & 10.90 & 0.70 \\
2004 & 1.33 & 3.69 & 0.00 & 104.03 & 6.83 & 0.97 \\
$2007 \mathrm{a}$ & 1.51 & 4.10 & 0.00 & 212.99 & 6.10 & 0.91 \\
$2007 \mathrm{~b}$ & 1.48 & 4.08 & 0.50 & 177.28 & 7.18 & 0.97 \\
\hline
\end{tabular}

length is a measure for the wavelength of thickness variations within the data set, with space and time information mixed. In $\varepsilon_{\text {mean }}(50 \mathrm{~m})$, for example, all wavelengths greater than $50 \mathrm{~m}$ are included. A comparison of the two lessdeformed ice regimes $(2001,2007)$ shows that for short profile lengths, $\varepsilon_{\text {mean } 2001}$ was higher than $\varepsilon_{\text {mean } 2007}$ and vice versa for longer profile lengths (Figure 5a, left). This indicates that spatial variability in the 2001 data set occurred on shorter-length scales than in the 2007 data set. In other words, on length scales longer than $10 \mathrm{~km}$, the MYI cover in 2001 was even more homogeneous than the FYI cover in 2007. But 2007 covered a much larger area and a much longer time span, i.e., larger variations can naturally be expected. So, this conclusion is only valid for the data sets themselves and cannot be taken as a statement for the complete ice-thickness distribution of the TPD in the particular year. Haas et al. [2008] highlighted the remarkable self-similarity of all 2007 profiles. $\varepsilon_{\text {mean }}$ can be taken as a quantification of this similarity. In the area covered in 2007 , on $100 \mathrm{~km}$ sections over a time span of 1.5 months, the deviation of the section means to the overall mean was not greater than $0.15 \mathrm{~m}$, which is indeed remarkably low. For 2001 , the same applies to profile lengths of even $15 \mathrm{~km}$, but here a time span of only 1 month is covered and a shorter total profile length is found. In 2004, a higher $\varepsilon_{\text {mean }}$ suggests a lower self-similarity of the obtained thickness profiles, and this even with a smaller extent of the survey area than in 2007.

[28] In 2001 and 2007, $\varepsilon_{\text {mod }}$ reached $0.2 \mathrm{~m}$ for a subsection length of $50 \mathrm{~km}$. In 2004 , the minimum value of $\varepsilon_{\text {mod }}$ was still as high as $0.6 \mathrm{~m}$ for a section length of $100 \mathrm{~km}$. The dependence of $\varepsilon_{\text {mod }}$ on the subsection length $l$ showed a different behavior than for $\varepsilon_{\text {mean }}$. The modal standard error $\varepsilon_{\text {mod }}$ was characterized by more abrupt changes (Figure 5a, right), which are based on the fact that the modal thickness reflects just a single thickness out of the distribution, namely, the maximum, whereas all others are neglected and it means that there are other frequent thickness classes which differ significantly from the dominant one. The profile length for which $\varepsilon_{\text {mod }}$ starts to decrease for the first time is probably correlated to the length of deformed sea-ice sections, since

Table 4. The Three Lognormal Fit Parameters for Sail Density, the Mean and Modal Sail Density, and the Correlation $r$ Between Fit and Measurements

\begin{tabular}{ccccccc}
\hline Year & $\sigma$ & $\mu$ & $\theta$ & $d_{\text {mean }}(\mathrm{m})$ & $d_{\max }(\mathrm{m})$ & $r$ \\
\hline 2001 & 0.25 & 2.52 & 7.80 & 5.01 & 3.90 & 0.95 \\
2004 & 0.24 & 3.01 & 14.35 & 6.52 & 4.85 & 0.99 \\
$2007 \mathrm{a}$ & 0.65 & 1.70 & 1.60 & 5.15 & 2.00 & 0.99 \\
$2007 \mathrm{~b}$ & 0.33 & 2.32 & 7.10 & 3.68 & 2.08 & 0.99 \\
\hline
\end{tabular}




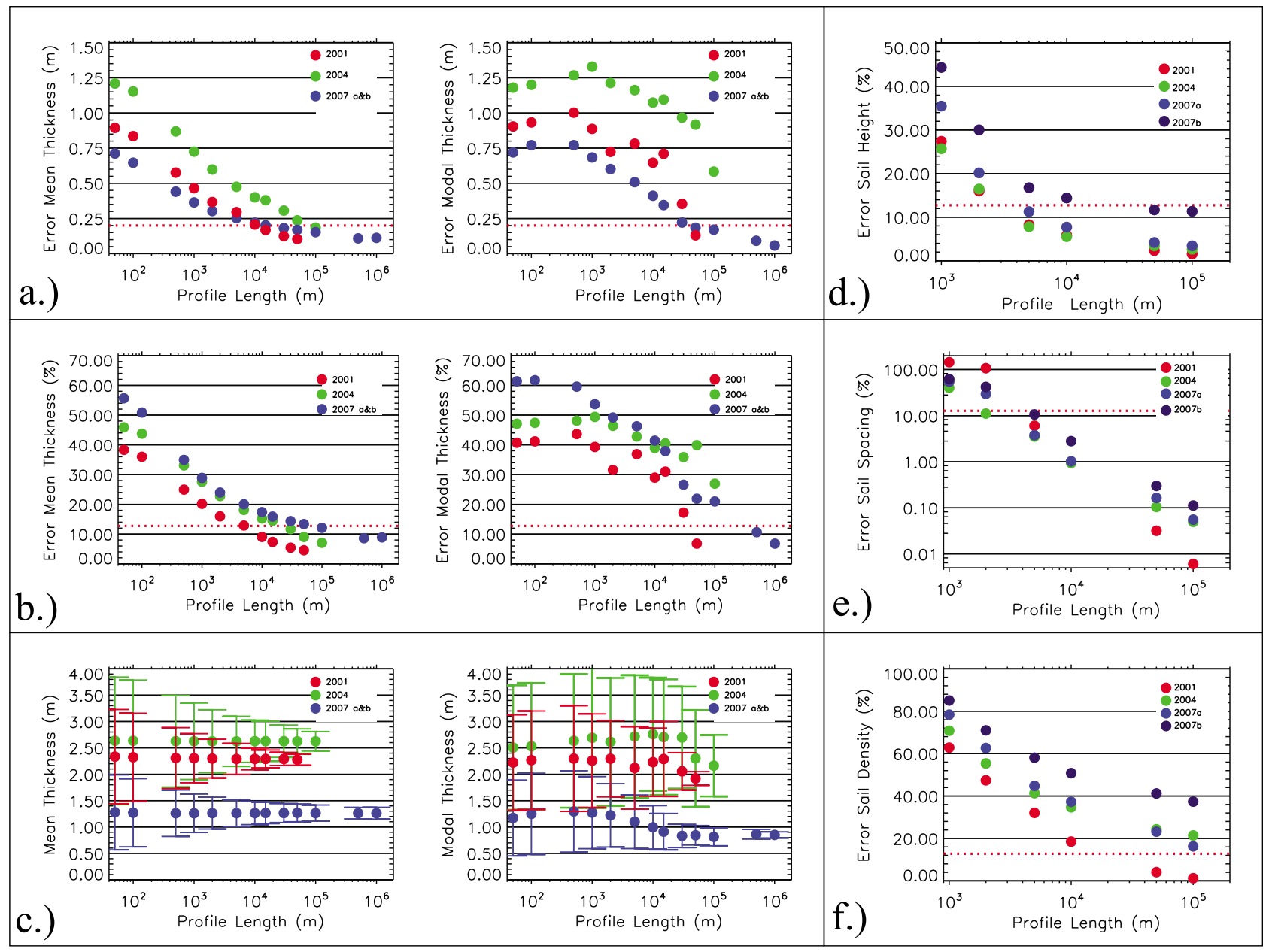

Figure 5. Standard error $\varepsilon$ versus profile length. (a) Absolute value of $\varepsilon$ of mean thickness (left) and modal thickness (right). The red line denotes the threshold for reliability of $0.2 \mathrm{~m}$. (b) $\varepsilon$ in percent of the mean thickness (left) or modal thickness (right). (c) Circles are mean thickness (left) and modal thickness (right) and error bars indicate $\varepsilon$. (d) $\varepsilon$ of mean ridge-sail heights as percentage of the mean. (e) $\varepsilon$ of mean ridge spacing as percentage of the mean. (f) $\varepsilon$ of mean ridge density in percentage of the mean. Except in Figure 5a, the red dotted line marks a $12.75 \%$ threshold. This threshold is aligned with the threshold for reliable mean thickness measurements of Wadhams [1997].

modes of level-ice sections must dominate those of deformed sections. Positions where a steeper decline of $\varepsilon_{\text {mod }}$ starts probably mark the minimum length for which the main ice class becomes dominant. The magnitude of the decline reflects the ice-thickness difference between the dominant and the second-most-frequent thickness class. This is the difference of the MYI and FYI modes in the 2001 data (see section 3.6), but also the occurrence of thin ice sections with a mode of $0.1 \mathrm{~m}$ are a reason for abrupt declines in $\varepsilon_{\text {mod }}$. In the MYI regime of 2004, the jump of $\varepsilon_{\text {mod }}$ occurs at a larger length than in 2001 and 2007 because thickness classes are present which differ significantly from each other but are more equally frequent than in the MYI regime of 2001. This is also indicated by the larger FWHM (Table 1) of the 2004 data. In the more homogeneous FYI regime of 2007, $\varepsilon_{\text {mod }}$ is generally smaller and shows no abrupt declines because the different dominant thickness classes are similar in thickness (smaller FWHM). Strictly speaking, with an $\varepsilon_{\text {mod }}$ of more than $0.2 \mathrm{~m}$, like in the 2004 data, the assignment of just a single modal thickness to the study region is not warranted.

[29] Since the mean and mode of a thickness distribution are not equal, modes of short profiles more likely reflect the overall mean thickness than the overall modal thickness (Figure 5c, right). This is easier to understand if we imagine a section length of only one sample. Then the mean of all modes of these one-sample sections is naturally equal to the overall mean thickness. Beyond a certain section length, the mean modal thickness decreases until it is equal to the overall modal thickness. In the less deformed FYI regime of 2007 from $30 \mathrm{~km}$ length onward, the true modal thickness was achieved; in the 2001 MYI regime from $50 \mathrm{~km}$ length onward and in the heterogeneous and more deformed 2004 MYI regime, not even at $100 \mathrm{~km}$ length.

[30] We summarize that for a clear characterization of a sea-ice regime with respect to its mean thickness, survey lengths of 10 to $15 \mathrm{~km}$ may be necessary in relatively homogeneous MYI or FYI regimes such as 2001 and 2007. 


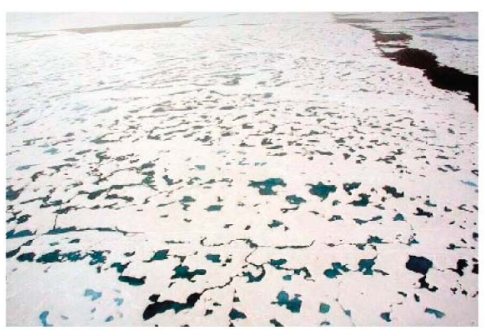

a) 2001

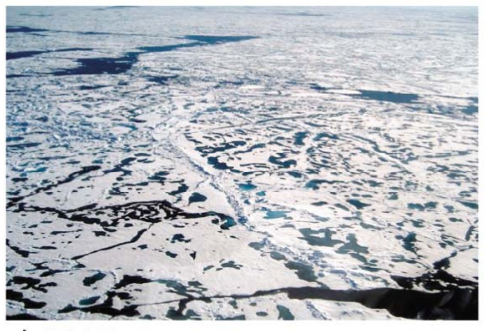

c) $2007 a$

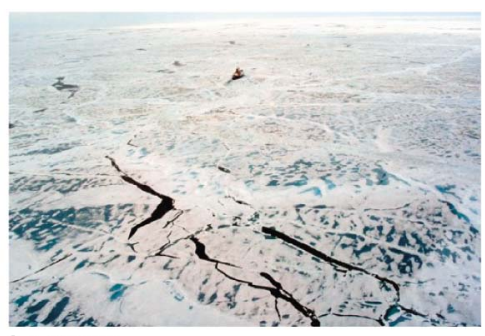

b) 2004

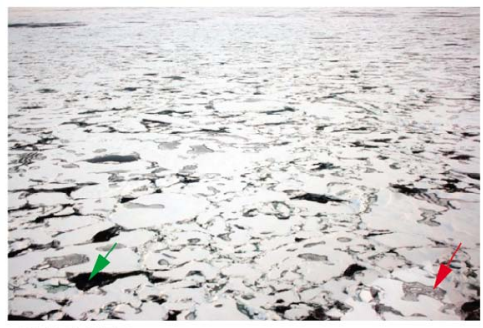

d) $2007 \mathrm{~b}$

Figure 6. Aerial photographs of typical sea-ice conditions for all four data sets. (a) Mid-August melt pond concentration is lowest of the four data sets and all ponds are refrozen. (b) End of July melt ponds are open. (c) Beginning of August melt ponds are open and mostly dark colored. (d) Mid-September melt ponds are refrozen. The red arrow points to a refrozen melt pond, and the green arrow points to a thaw hole.

In heterogeneous and deformed MYI regimes like 2004, a minimum of $100 \mathrm{~km}$ can be required. For a representative modal thickness profile, lengths of $50 \mathrm{~km}$ are necessary in homogeneous MYI and FYI regimes, and at least $500 \mathrm{~km}$ may be necessary in heterogeneous MYI regimes, where an assignment of a dominant modal thickness can even be questionable at all.

[31] The standard error $\epsilon$ in dependence of section length $l$ for sail height, spacing, and density is shown in Figures 5d, $5 \mathrm{e}$, and $5 \mathrm{f}$ in terms of percentage of the mean. Likewise, regarding the standard error of the mean and modal thickness, a value of $12.75 \%$ of the mean was taken as a threshold for representative results. For a section length of $100 \mathrm{~km}$, mean sail spacing could be obtained with the lowest standard error, followed by mean sail height and mean sail density, which has the highest error. The small standard error for spacing accounts for the clustering of sail heights with a preferred spacing of between 6 to $11 \mathrm{~m}$ within each cluster. In other words, only short profile lengths are necessary to obtain typical spacing of sail heights within deformation zones. A better quantity to describe the distribution of deformation zones as a whole is the sail density. Since the pattern in which deformation zones appear is less regular than sail spacing within a deformation zone, the standard error of sail density is higher. For sail density, the length of the data set correlates with the standard error. Hence, 2001 shows the lowest standard errors, and the longest data set of $2007 \mathrm{~b}$ shows the largest ones. This result indicates that compared to sea-ice thickness, the distribution of deformation zones cannot be associated with huge homogeneous regimes of FYI or MYI as is possible with thickness.

\subsection{Melt Ponds}

[32] Melt ponds were detected with the method described in section 2.3, which is applicable for open melt ponds only.
Open melt ponds were present during the 2004 and 2007a surveys, whereas almost all of the melt ponds were refrozen during 2001 and 2007b. Henceforth, only the 2004 and 2007a data were taken for melt pond coverage determination. In Figure 3, positions having melt ponds, which are defined as laser data dropouts over ice thicker than $0.1 \mathrm{~m}$, are marked with light blue bars. Mean melt pond concentrations amounted to $15 \pm 14 \%$ for 2004 and $15 \pm 11 \%$ for $2007 \mathrm{a}$, where the errors are standard errors for profile lengths of $35 \mathrm{~km}$. These results can be compared with visual observations of melt pond concentrations during each expedition, for which the 2001 melt pond concentration varied between $10 \%$ and $30 \%$ (all refrozen) [Haas and Lieser, 2003], 2004 between 30\% and 40\% (during the last two flights partially refrozen) [Lieser, 2005], and 2007 melt pond concentration between $20 \%$ and up to $50 \%$ (2007b all refrozen or transformed to thaw holes) [Schauer, 2008]. The difference between laser-derived melt pond concentration and visual observations or aerial photography (Figure 6) suggests that the laser provides an underestimation of the true concentration. In Figure 7, the effect of open melt ponds on the overall thickness distributions of 2004 and 2007a is shown. It can be seen that ponded ice is on average thinner than pond-free ice even with the water column of the melt pond included in the ice thickness value, since the HEM instrument measures the distance from the surface of melt ponds to the ice-ocean interface. Furthermore, Figure 7 shows that melt ponds preferably form on ice with a thickness less than or equal to the modal ice thickness, which was $1 \mathrm{~m}$ thicker in 2004 than in 2007. Additional information about the brightness and the color of melt ponds is known from visual observations. The 2007 melt ponds were on average darker than those during 2001 and 2004 (Figure 6), which accounts for thinner or no ice below the melt pond. 


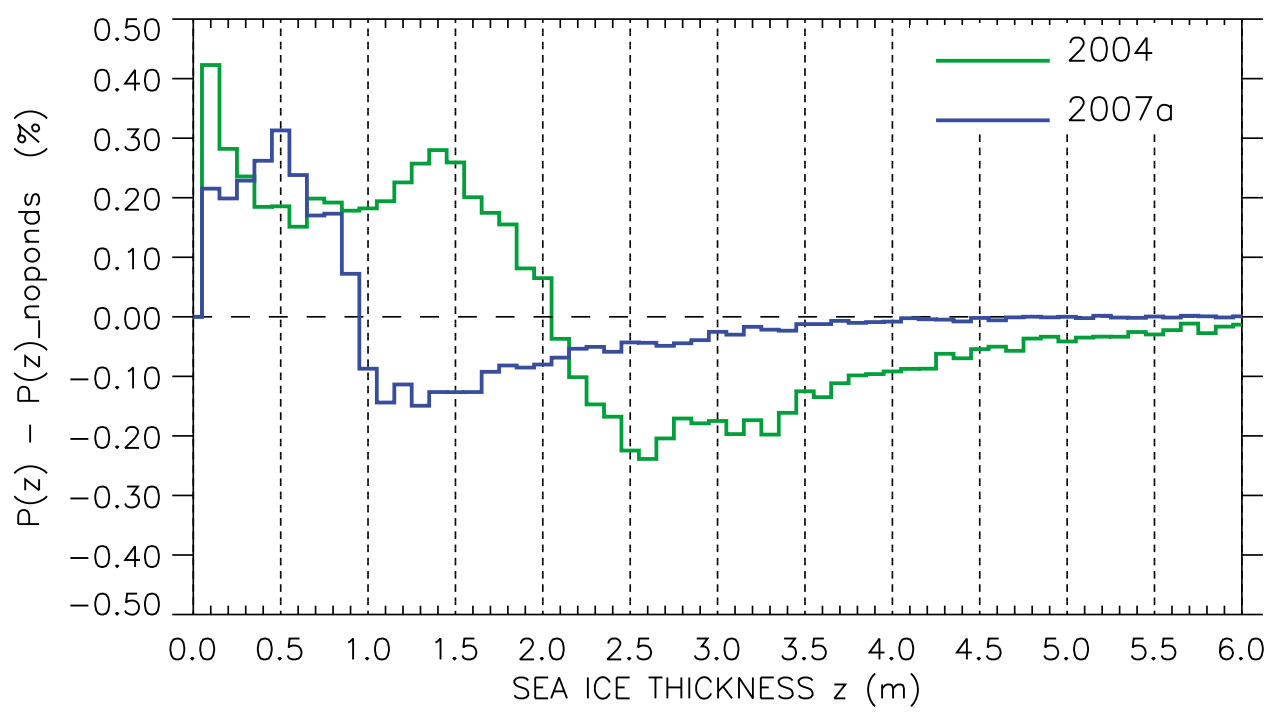

Figure 7. $P(z)-P(z)_{n o p o n d s}$ is the difference between sea-ice thickness distributions including ponded ice and excluding ponded ice. Above zero refers to ice-thickness ranges which are overrepresented in ponded ice, and below zero refers to an underrepresentation in ponded ice.

[33] The equal amount of melt pond concentration in 2004 and 2007a suggests that overall surface melting was not stronger in either of the 2 years. However, since the ice was thinner in 2007, the same amount of melt ponds triggered different processes. Not only are melt ponds on thinner ice more easily transformed into thaw holes, but their darker surface also amplifies the albedo feedback. In 2007b, many thaw holes emerged (Figure 6d) which reduced the ice concentration at some locations, e.g., at the Pacific-Siberian ice edge (Figure 1d), significantly. Once melt ponds are transformed into thaw holes and the sea ice concentration is lowered, the thinning of ice is even accelerated as described in section 3.7. The question why the ice concentration was lower close to the ice edge but not over widespread areas of the 2007 FYI cover is discussed in section 3.8.

[34] Furthermore, we should note that large amounts of thaw holes probably reduce the mechanical strength of the sea-ice cover. Together with the 2007 persistent southerly winds over the Pacific sector of the Arctic Ocean [Maslanik et al., 2007b], the thaw hole-related fragmentation of the sea ice cover may be a further reason for the increased drift velocity in 2007 , as a fragmented sea ice cover is easier to move [Rampal et al., 2009].

\subsection{Level Ice}

[35] Level ice was identified using two criteria. First, the numerical differentiation of sea-ice thickness along the profile using a three-point Lagrangian interpolator must be $<0.04$, and second, level-ice sections must extend at least $100 \mathrm{~m}$ in length, which is approximately two times the footprint of the HEM Bird. Such identified level-ice sections are marked black in Figure 3. Compared to the level-ice definition of former studies [e.g., Wadhams and Horne, 1980], which defined a measurement point as level if either of the two points $10 \mathrm{~m}$ left or right of it did not differ more than $0.25 \mathrm{~m}$ in draft, our criterion is more strict and the amount of level ice identified (see Table 1) is lower than visual observations of the sea-ice cover imply. However, a definition of level ice is always to a certain degree arbitrary, and for our purpose, which is to extract the thermally grown ice thicknesses, we want to minimize the amount of deformed ice passing the level-ice filter as much as possible. With all the deformed sea ice removed, $P(z)$ becomes normally distributed (Figure 8) and mean and modal thickness agree to within $\pm 0.1 \mathrm{~m}$. The 2004 and $2007 \mathrm{~b}$ data sets have a second mode at $0.1 \mathrm{~m}$, representing thin ice on refrozen leads. Of particular interest is the second mode in the 2001 data of $1.1 \mathrm{~m}$, representing sporadically occurring first-year ice. It is sporadic because the FYI mode $\pm 0.2 \mathrm{~m}$ sums up to not more than $6 \%$ of the level ice, which is $0.96 \%$ of the total data set. For 2001 and 2004, level ice of even $3 \mathrm{~m}$ and thicker occurred, which is most probably deformed ice which accidentally fulfilled the level-ice criterion. The shift of the modal thicknesses in the 2001 and $2007 \mathrm{~b}$ data from $2.0 \mathrm{~m}$ and $0.9 \mathrm{~m}$ in the complete thickness distribution to 1.8 $\mathrm{m}$ and $0.8 \mathrm{~m}$ in the level-ice distribution (Tables 1 and 5) can be explained with the strict criterion and the consequence is that not $100 \%$ of the level ice is identified. Another explanation could be the uncertain relation between modal and level-ice thickness. The mean length of level-ice areas is longest for 2001, a little bit shorter for 2007, and shortest in the 2004 data (Table 5).

[36] When we interpret the second mode at $1.1 \mathrm{~m}$ in the 2001 level-ice histograms as a FYI mode (Figure 8), the level-ice thickness of $2007 \mathrm{a}$ and $2007 \mathrm{~b}$ was only $0.2 \mathrm{~m}$ and $0.3 \mathrm{~m}$ thinner than level FYI in 2001. Compared to previous studies, this lies within the interannual variation of melting and freezing rates. Haas and Eicken [2001], for instance, observed changes of level ice thickness within a summer FYI cover in the Laptev Sea of $0.3 \mathrm{~m}$ between 1995 and 1996, and Perovich et al. [2008] showed yearly melting rates at the North Pole between $0.4 \mathrm{~m}$ and $0.7 \mathrm{~m}$. Therefore, 2007 was not exceptional with regard to melting rates, at least not within the pack. This result is also supported by 


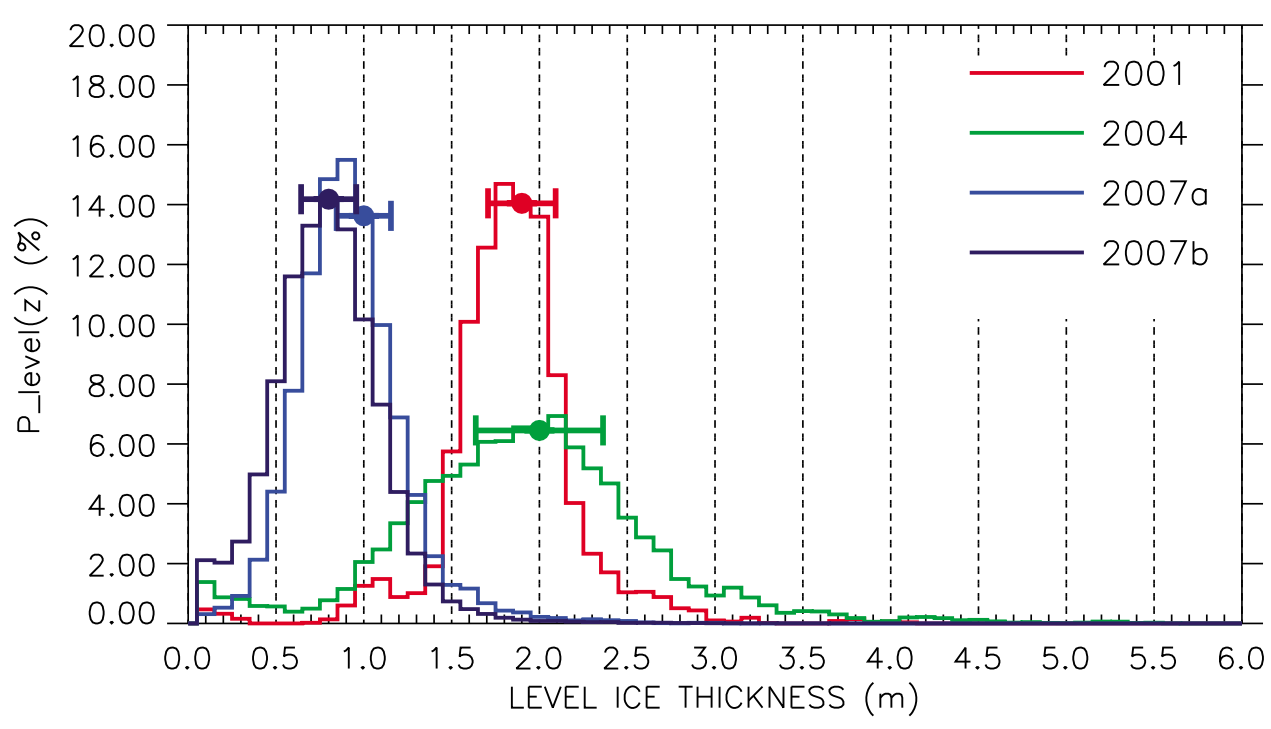

Figure 8. Level-ice thickness distributions. Circles mark mean sea-ice thicknesses, and error bars indicate their standard deviations.

Kwok et al. [2009], who found a considerably thinner Arctic MYI cover in 2007 but a negligible trend toward thinner FYI.

\subsection{Dependence of Thickness on Sea-Ice Concentration}

[37] Accounting for the lower albedo of an open ocean, a decreasing sea-ice concentration causes additional heat gain of the ocean via short-wave insolation and therefore causes additional melting. Hence, it is of interest to analyze the relation between level sea-ice thickness and open-water content for all three data sets. According to the instrument accuracy of $\pm 0.1 \mathrm{~m}$, our definition of open-water content is the fraction of the thickness distribution function where ice thickness is lower than $0.1 \mathrm{~m}$.

[38] For the analysis of the dependence of level-ice thickness on ice concentration, we picked all modal thicknesses emerging for each flight. This time not only the overall maximum in the distribution was picked, but every local maximum as well. This highlights the distribution of larger areas with the same level-ice thickness within each flight. Plots of open water fraction versus thickness modes are shown in Figure 9. In 2001, the majority of level-ice modes fell within a range between 1.6 and $2.0 \mathrm{~m}$, independent of sea-ice concentration, although a maximum open-water content of $15 \%$ could be observed (Figure $9 \mathrm{a}$ ). The profiles with an open-water content of $>10 \%$ were obtained in the region of the North Pole. Two modes are distinctly thinner and had a thickness of 1.0 and $1.1 \mathrm{~m}$, representing first-year ice. The 2004 data showed a much larger scattering of modal thicknesses, ranging from $0.1 \mathrm{~m}$ to $3.6 \mathrm{~m}$, where the majority of the modes lay within 1.5 and $2.0 \mathrm{~m}$ (Figure 9b). Owing to the low fraction of open water $(6 \%)$, the variability in sea-ice concentration was too low for the identification of a significant relationship between ice concentration and level-ice thickness. The same applied for 2007a, where no significant amount of open water was present in the data (Figure 9c). Here the modes were much less scattered, and the majority of the modal thicknesses were between 0.6 and $1.0 \mathrm{~m}$. The only significant dependence on open water could be observed in the $2007 \mathrm{~b}$ data, where modal thickness decreased gradually with an increasing amount of open water (Figure 9d). For profiles with open-water content of below $10 \%$, the modes were concentrated between 0.6 and $1.0 \mathrm{~m}$, as for 2007a. Ignoring the modes of thin ice, which represent young ice formed in September 2007, this decreasing behavior can be described by a linear relationship:

$$
\begin{aligned}
Z_{2007 b}(W)= & -0.02 \cdot W+0.94 \\
& \text { with } 10 \%<W<40 \%, r=0.7,
\end{aligned}
$$

where $W$ is the open-water content and $Z$ is the level-ice thickness. There are several explanations for the absence of a thickness dependence on open water content in 2001. First, the maximum open water fraction was only $15 \%$; second, open water spots occurred in huge open leads and not in the form of a fragmented ice cover as in 2007; and third, heat gain of the ocean and downwelling short-wave radiation were not as high as in 2007 [Kay et al., 2008; Perovich et al., 2008]. The gradient of increasing open water content in $2007 \mathrm{~b}$ was directed toward the Pacific sea-ice margin of the 2007 sea-ice cover. Therefore, we continue the discussion of the thin $2007 \mathrm{~b}$ sea ice in section 3.8 .

Table 5. Mean and Modal Thickness of Level Ice and the Mean and Maximum Length of Continuous Level-Ice Sections

\begin{tabular}{lcccc}
\hline Year & $\begin{array}{c}\text { Mean } \\
\text { Thickness } \\
(\mathrm{m})\end{array}$ & $\begin{array}{c}\text { Modal } \\
\text { Thickness } \\
(\mathrm{m})\end{array}$ & $\begin{array}{c}\text { Mean } \\
\text { Length } \\
(\mathrm{m})\end{array}$ & $\begin{array}{c}\text { Max } \\
\text { Length } \\
(\mathrm{m})\end{array}$ \\
\hline 2001 & $1.89 \pm 0.37$ & 1.8 & $160 \pm 77$ & 552 \\
& & 1.1 & & \\
2004 & $1.96 \pm 0.72$ & 0.1 & $148 \pm 54$ & 426 \\
& & 2.1 & & \\
$2007 \mathrm{a}$ & $0.97 \pm 0.31$ & 0.1 & $158 \pm 69$ & 680 \\
$2007 \mathrm{~b}$ & $0.84 \pm 0.31$ & 0.8 & $154 \pm 66$ & 888 \\
& & 0.1 & & \\
\hline
\end{tabular}




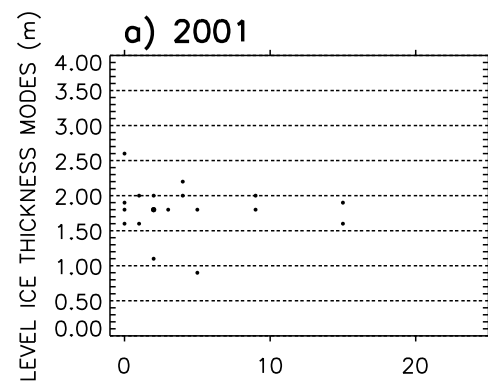

b) 2004

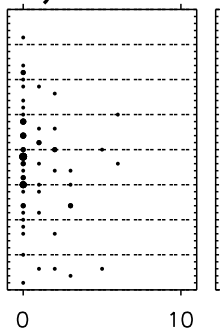

c) $2007 a$

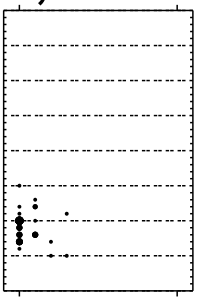

OPEN WATER FRACTION (\%) d) $2007 \mathrm{~b}$

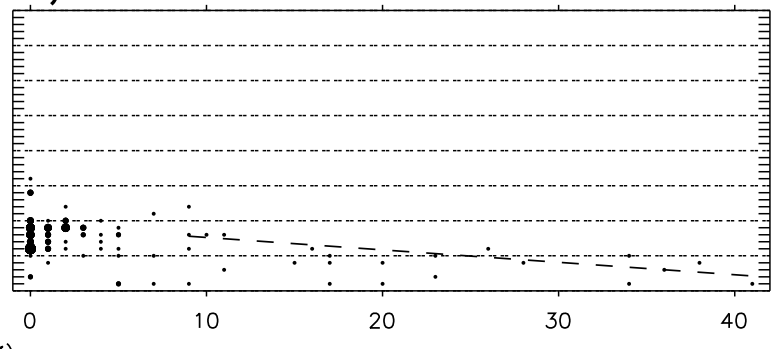

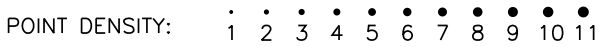

Figure 9. Modes of level-ice thickness of individual $35 \mathrm{~km}$ sections (18.5 km in 2001) plotted versus open water fraction. All modes, not only the dominant modes, of all individual sections are plotted. The circle size denotes the point density, i.e., the number of modes plotted on the same position. The dashed line in Figure $9 \mathrm{~d}$ is a linear fit to level-ice modes thicker than $0.1 \mathrm{~m}$ and with an open water content of $>10 \%$.

\subsection{Thickness Gradients Toward the Ice Edge}

[39] The 2004, 2007a, and 2007b data sets allow the study of thickness gradients from the sea-ice edge into the closed ice pack. In Figure 1, the different distributions of sea-ice concentration along the three ice edges are visible. The 2004 sea-ice edge north of Fram Strait was exceptionally far north and showed a sharp transition from open water to high ice concentrations (Figure 1b). Of similar sharp appearance was the sea-ice margin north of the Barents Sea in the 2007a data (Figure 1c). Moreover, the location of the edge remained stable during the time of rapid sea-ice decline in August and September 2007. The 2007 sea-ice decline was rather pronounced at the Pacific-Siberian ice margin, where a widespread decrease in ice concentration was visible already in August (Figure 1c and Figure 1d).

[40] The gradients of thickness and open-water fraction $P(0)$ along the ice edge are shown in Figure 10. On average, each sample represents a $35-\mathrm{km}$-long flight track. They are displayed as a function of latitude, since transects perpen- dicular to the three ice edges are basically south-north oriented. As we are interested in thickness changes due to melting and freezing, we only considered level-ice thickness. The thickness surveys were performed in time periods of 18 days (2004), 8 days (2007a), and 22 days (2007b), which are time spans where melting and freezing can proceed substantially. To account for temporal changes during the time period of the survey, thickness and open-water samples in Figure 10 are color-coded according to the time progressed. Surface melting could be observed during the first 15 days of 2004 and during 2007a by the presence of open melt ponds. During the last 3 days of the 2004 surveys and during $2007 \mathrm{~b}$, thin ice emerged on the melt ponds as an indicator of a decline in surface melting. However, whether these are signs for a thinning or thickening within the survey period cannot easily be answered here, since the amount of bottom melt can be significant even when surface melting comes to a halt [Perovich et al., 2003]. a) 2004

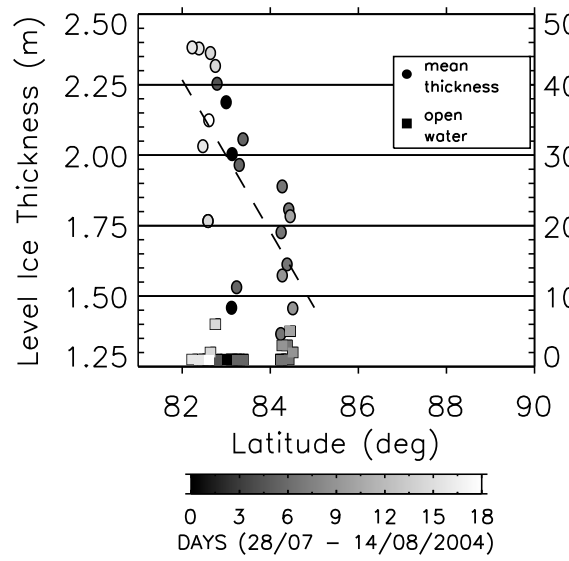

b) $2007 a$

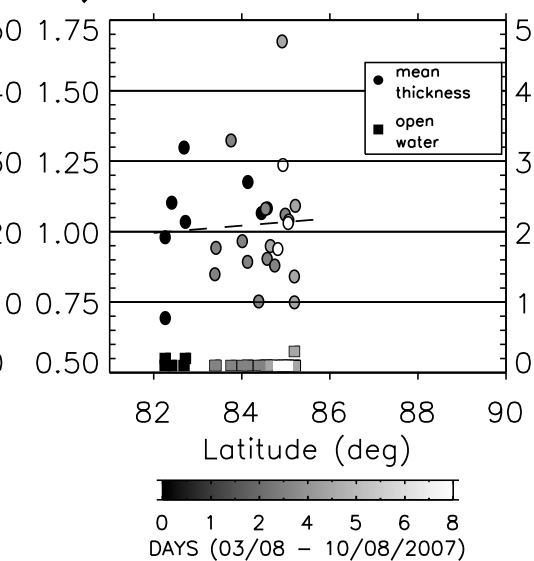

c) $2007 \mathrm{~b}$

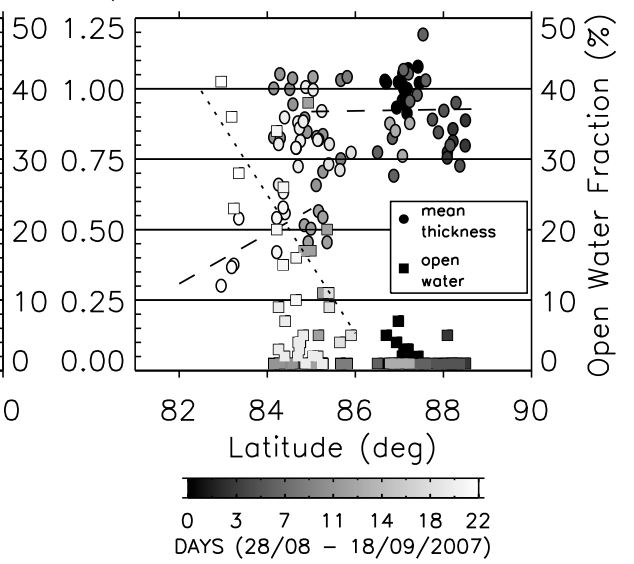

Figure 10. Mean level-ice thickness (circles) of individual $35 \mathrm{~km}$ sections and open water fraction (squares) plotted versus latitude. Shaded areas indicate the day within the measurement period, where black is the first day and white the last. A circle and square of the same color correspond to one individual section. Dashed lines are linear fits of the level-ice thickness. Dotted line (only in Figure 10c) is a linear fit to the open water fraction. 
[41] In 2004, a decrease of mean level-ice thickness from $2.25 \mathrm{~m}$ to $1.75 \mathrm{~m}$ could be observed toward higher latitudes between $82^{\circ} \mathrm{N}$ and $85^{\circ} \mathrm{N}$. Open-water content remained lower than $8 \%$ and showed no significant gradient but a slightly higher concentration of open leads $(8 \%)$ around $82.8^{\circ} \mathrm{N}$ and $84.5^{\circ} \mathrm{N}$ (Figure $10 \mathrm{a}$ ). The 2007 a data showed no trend from the margin at $82^{\circ} \mathrm{N}$ up to $85.5^{\circ} \mathrm{N}$ either in mean level-ice thickness or in open-water content, which remained lower than 3\% (Figure 10b). In comparison, 2007b showed significant changes in mean level-ice thickness from values of $0.35 \mathrm{~m}$ at the margin at $83^{\circ} \mathrm{N}$ to values of $0.75 \mathrm{~m}$ at $85.5^{\circ} \mathrm{N}$, whereas north of $85.5^{\circ} \mathrm{N}$, level-ice thickness remained constantly scattered around a mean of $0.9 \mathrm{~m}$. The same was true for the open water content, which decreased from a maximum of $40 \%$ at the ice margin to a mean of $3 \%$ at $85.5^{\circ} \mathrm{N}$. Farther north, the maximum open water content was lower than $8 \%$ (Figure 10c). These results show that, similarly to the Beaufort Sea [Perovich et al., 2008], melting rates in the central Arctic in 2007 close to the Pacific sea-ice edge were increased, but not within the pack. The thickness gradients in 2004 and $2007 \mathrm{~b}$ from the edge toward the north can be described by the following linear fits:

$$
\begin{aligned}
Z_{2004}(L)= & -L \cdot 0.27+24.35, \\
& \text { with } 82^{\circ} \mathrm{N}<L<85^{\circ} \mathrm{N}, r=0.63 \\
Z_{2007 b}(L)= & L \cdot 0.09-7.0, \\
& \text { with } 82^{\circ} \mathrm{N}<L<85.5^{\circ} \mathrm{N}, r=0.53,
\end{aligned}
$$

where $Z$ is the mean level-ice thickness, $L$ is the latitude, and $r$ is the correlation coefficient. The evolution of ice thickness in time showed no significant correlation in 2004 and 2007a. In 2007b, a thinning of ice during the time period of the survey was implied, but this can be explained by a thinning with increasing open water content as well.

[42] Compared to previous studies on meridional sea-ice thickness gradients in the region of the Fram Strait and north of it [Wadhams and Davis, 2000b], where the thickness gradient was positive toward the north, the 2004 negative gradient of mean level-ice thickness from $82^{\circ} \mathrm{N}$ to $85^{\circ} \mathrm{N}$ (Figure 10a) is somewhat surprising. It can be interpreted as a situation where older ice was situated in the south and younger ice was situated north of it. Probably the older ice was advected from north of Greenland, whereas the younger ice was advected from the Eurasian side of the TPD.

[43] The reason for the presence of a thickness and concentration gradient at the $2007 \mathrm{~b}$ ice edge is more difficult to find. Interestingly, the 2007a ice edge did not show such a gradient. Therefore, we pose the question why sea-ice concentration and thickness decreased gradually at the Pacific side but abruptly at the Atlantic side of the 2007 sea-ice cover. An obvious difference between both margins is that the Atlantic margin was stationary, whereas the Pacific margin retreated toward the North Pole during August and September (compare Figures 1c and 1d). This was a consequence of the general drift pattern of the TPD in JuneOctober 2007 parallel to the Atlantic sea-ice boundary caused by an anticyclonic surface wind anomaly [Ogi et al., 2008]. Considering this wind anomaly, which caused on-ice winds at the 2007 Pacific sea-ice margin, it is contrary to previous studies by Wadhams [2000a] that the Pacific sea-ice edge was diffuse instead of compact and abrupt. Another difference between both sea-ice edges was exceptional heat gain of the surface layer of the Arctic Ocean on the Pacific side which could not be observed on the Atlantic side of the ice cover [Steele et al., 2008; Perovich et al., 2008]. Considering both the heat gain and the wind direction, a plausible explanation could be the transport of warmer air masses from the open ocean beyond the Pacific sea-ice margin into the pack. This caused additional surface melting whereby melt ponds were transformed into thaw holes, which amplified the albedo feedback. Further within the ice pack, the warmer air masses cooled down and melting rates were reduced.

\section{Conclusions and Outlook}

[44] We have presented high-resolution HEM sea-ice thickness data from the Arctic Trans-Polar Drift (TPD) in the summers of 2001, 2004, and 2007. These data provided the opportunity to compare thickness distributions and surface properties of sea-ice regimes consisting of predominantly first-year ice (2007) or predominantly multiyear ice $(2001,2004)$ with different dynamic histories. Furthermore, the data are of special importance, since regular activities of ULS submarine surveys to obtain sea-ice draft became less frequent during the 2000s. These data can be used for validation of various model studies or sea-ice thickness results from satellite altimetry techniques. The 2001 and 2007 surveys were situated more upstream within the TPD, closer to the North Pole and toward the Pacific side of the Arctic Ocean, and the 2004 surveys more downstream within the TPD in the area north of the Fram Strait. September mean sea-ice thickness in the upstream TPD decreased from $2.29 \mathrm{~m}$ in 2001 to $1.22 \mathrm{~m}$ in 2007 . Downstream TPD mean sea-ice thickness was $2.63 \mathrm{~m}$ in 2004, which is a continuation of the decreasing trend in the region north of the Fram Strait shown by Wadhams and Davis [2000b].

[45] This work focused on a detailed analysis of sea-ice thickness distributions and surface properties of the sea-ice cover and is therefore a continuation of the study of Haas et al. [2008] which is partially based on the same data sets but focused more on the evolution of summer sea-ice thickness in the TPD since 1991. As a major conclusion, we found that MYI regimes can show similar modal thicknesses and at the same time different shapes of their distribution functions, for which a less deformed and homogeneous MYI regime was more self-consistent with a FYI regime in the same region but 6 years later. We conclude that the parameters FWHM of a distribution function and the curvature of the tail of a distribution function depend more on the location within the TPD, e.g., locations with a different degree of drift convergence, rather than on the age of the ice. For instance, the MYI thickness distribution downstream of the TPD showed a larger FWHM and a lower curvature $\mathrm{B}$, indicating the presence of different types of MYI or a heavier degree of deformation.

[46] The three pressure-ridge parameters sail height, sail spacing, and number of sails per kilometer were obtained. We found that sail height is a poor parameter to estimate the 
mean or modal thickness within a pack, since mean sail heights between a thin FYI regime in 2007 and a more than $50 \%$ thicker MYI regime in 2004 differed by only $10 \%$. Likewise small was the difference of modal sail spacings between the studied ice regimes, agreeing within a spacing interval of 6 and $11 \mathrm{~m}$. These small modal spacing values represent the average sail spacing within a deformation zone and not the distance between two such zones. The sail density showed different behavior, where both mean and mode increased with transition into the convergent regime north of Fram Strait. Hence sail densities are more appropriate to describe the state of deformation of a regime than sail spacing or sail height.

[47] To ensure the statistical reliability of our measurements, standard errors of the mean, and mode for different profile lengths were calculated. Honoring the $12.75 \%$ of the mean criterion of significance of Wadhams [1997], the mean thickness of all 3 years was achieved with an acceptable standard error. The required length of a thickness profile depends on the regional variability of ice-thickness types present in the study area and on the degree of deformation. An absolute standard error of the mean thickness of $0.2 \mathrm{~m}$ or below could be achieved for less deformed and homogeneous MYI and FYI regimes in 2001 and 2007 at survey lengths between 10 and $15 \mathrm{~km}$ and for a heavier deformed and heterogeneous MYI regime in 2004 at survey lengths of $100 \mathrm{~km}$ or more, indicating its larger regional variability due to the presence of different ice-thickness types. Standard errors of modal thickness remained constantly high until a sufficient profile length was reached, where the error dropped abruptly to lower values. A standard error for modal thickness of $0.2 \mathrm{~m}$ was achieved for profile lengths of $50 \mathrm{~km}$ in the MYI and FYI regime of 2001 and 2007, but it remained as high as $0.6 \mathrm{~m}$ for $100-\mathrm{km}$-long transects in the heterogeneous and deformed MYI regime in 2004. Most pressure ridge parameters can be obtained with standard errors lower than $12.75 \%$ of the mean, except sail density. Here the standard error increased with the length of the data set in all years, indicating that deformation zones do not distribute as homogeneously as we have observed for sea-ice thickness.

[48] Concentration of open melt ponds was estimated for each year in early August. Later in the year, the melt ponds were already refrozen. We observed equal melt pond concentrations of $15 \%$ on FYI in 2007 and MYI in 2004, likely an underestimation of the true melt pond coverage. Melt ponds form preferably on ice thinner than the modal thickness. On thin first-year ice, they can cause abrupt reductions of sea-ice concentration when the bottom melts through to the underlying ocean, as we observed for the Pacific Siberian sea-ice edge in 2007.

[49] A comparison of thermodynamically grown sea ice between the years was done by separating level-ice sections from the complete data sets. Level-ice thicknesses of the same type, i.e., FYI or MYI, respectively, were normally distributed and mean and mode agreed within $10 \mathrm{~cm}$. Comparison of 2007 level-ice thickness with sporadic FYI in 2001 showed a difference of $-0.2 \mathrm{~m}$ in 2007 , which lies within the expected interannual variation of freezing and melting rates. Therefore, thermodynamic growth conditions within the pack seemed not to be much different in 2007 despite the minimum extent in that summer. This is in agreement with results from Kwok et al. [2009], who found no negative trend of the thickness of Arctic FYI between 2003 and 2008.

[50] Meridional gradients of level ice were found in the 2004 and $2007 \mathrm{~b}$ data. Whereas the first gradient was caused by the advection of different ice types, the latter was a consequence of the proximate and strongly retreating ice edge. We speculate that the combination of persistent southerly winds in the TPD [Maslanik et al., 2007a; Ogi et al., 2008] and anomalous high sea surface temperatures in the Pacific sector of the Arctic Ocean [Steele et al., 2008] created warm on-ice winds which accelerated the formation of thaw holes on the thin FYI close to the sea-ice margin. This led to accelerated bottom melting [Perovich et al., 2008] and fragmentation of the sea-ice cover [Rampal et al., 2009] and to a retreat of the 2007 Pacific-Siberian ice edge. Further, we conclude that sea-ice thickness in the central Arctic Ocean depends more on the surrounding sea-ice concentration than on the latitude, which in turn makes sea-ice thickness measurements in a region with low sea-ice concentration less representative for the whole region.

[51] Some of the results presented here should be considered for future sea-ice thickness activities in the Arctic and their interpretations. The fact that satisfactory small standard errors of mean and modal thickness can be obtained on relatively short transects of approximately $15 \mathrm{~km}$ and $50 \mathrm{~km}$, at least in the central Arctic, indicates the high representativeness of airborne sea-ice thickness profiles in this part of the Arctic Ocean. This can be seen as a justification for an intensified continuation of sea-ice thickness monitoring using ice breaker-based HEM. Taking remote sensing data or model data of age, concentration, or drift of sea ice into account, thickness results from single transects may have a relevance to other regions of the Arctic, where these parameters are similar. On the contrary, in convergent ice regimes, such as north of Fram Strait, we suggest not to define obtained mean thicknesses as being representative for that region, when they were recorded on a total transect length of less than $100 \mathrm{~km}$. However, it is worthwhile to continue and expand HEM measurements in the Arctic to consolidate the presented results and to assess whether the statistical parameters in other convergent MYI regions are comparable to that of the MYI north of Fram Strait in 2004. Furthermore, laser-derived melt pond concentrations have to be validated by means of ground truthing during future field activities in the Arctic.

[52] Acknowledgments. We thank the crew of $R / V$ Polarstern, the helicopter crew of HeliService International $G m b H$ and all the people who helped with the measurements, especially Jan Lieser and Volker Leinweber, without whom these data would never have been collected. Additional funding was given by the EU project DAMOCLES. The paper was written during a visit at the University of Alberta, which was funded by the German academic exchange service (DAAD). Ice concentration data were downloaded from CERSAT/IFREMER (http://cersat.ifremer. fr/data/).

\section{References}

Bourke, R., and R. Garrett (1987), Sea ice thickness distribution in the arctic ocean, Cold Reg. Sci. Technol., 13, 259-280.

Budéus, G., and P. Lemke (2007), The expeditions ARKTIS-XX/1 and ARKTIS-XX/2 of the Research Vessel "Polarstern" in 2004, Rep. Polar Res., 544, 242 pp., Available at http://hdl.handle.net/10013/epic.10549. 
Comiso, J. C., C. L. Parkinson, R. Gersten, and L. Stock (2008), Accelerated decline in the Arctic Sea ice cover, Geophys. Res. Lett., 35, L01703, doi:10.1029/2007GL031972.

Davis, N., and P. Wadhams (1996), A statistical-analysis of Arctic pressure ridge morphology, J. Geophys. Res., 100, 10,915-10,925.

Eicken, H., W. Tucker, and D. Perovich (2001), Indirect measurements of the mass balance of summer Arctic sea ice with an electromagnetic induction technique, Ann. Glaciol., 33, 194-200.

Gerdes, R., and C. Koeberle (2007), Comparison of Arctic sea ice thickness variability in IPCC Climate of the 20th century experiments and in ocean-sea ice hindcasts, J. Geophys. Res., 112, C04S13, doi:10.1029/ 2006JC003616.

Giles, K. A., S. W. Laxon, and A. L. Ridout (2008), Circumpolar thinning of Arctic sea ice following the 2007 record ice extent minimum, Geophys. Res. Lett., 35, L22502, doi:10.1029/2008GL035710.

Haas, C. (2004), Late-summer sea ice thickness variability in the Arctic Transpolar Drift 1991-2001 derived from ground-based electromagnetic sounding, Geophys. Res. Lett., 31, L09402, doi:10.1029/2003GL019394.

Haas, C., and H. Eicken (2001), Interannual variability of summer sea ice thickness in the Siberian and central Arctic under different atmospheric circulation regimes, J. Geophys. Res., 106, 4449-4462, doi:10.1029/ 1999JC000088

Haas, C., and J. Lieser (2003), Sea ice conditions in the transpolar drift in August/September 2001: Observations during POLARSTERN cruise ARKTIS XVII/2, Rep. Polar Res., 441, 123 pp., Available at http:// hdl.handle.net/10013/epic.10446.

Haas, C., S. Gerland, H. Eicken, and H. Miller (1997), Comparison of seaice thickness measurements under summer and winter conditions in the Arctic using a small electromagnetic induction device, Geophysics, 62, 749-757.

Haas, C., S. Hendricks, and M. Doble (2006), Comparison of sea ice thickness distribution in the Lincoln Sea and adjacent Arctic Ocean in 2004 and 2005, Ann. Glaciol., 44, 247-252.

Haas, C., A. Pfaffling, S. Hendricks, L. Rabenstein, J.-L. Etienne, and I. Rigor (2008), Reduced ice thickness in Arctic Transpolar Drift favors rapid ice retreat, Geophys. Res. Lett., 35, L17501, doi:10.1029/ 2008 GL034457.

Haas, C., J. Lobach, S. Hendricks, L. Rabenstein, and A. Pfaffling (2009), Helicopter-borne measurements of sea ice thickness, using a small and lightweight, digital EM system, J. Appl. Geophys., 67, 234-241.

Hendricks, S. (2009), Validierung von altimetrischen Meereisdickenmessungen mit einem helikopterbasierten elektromagnetischen Induktionsverfahren, Ph.D. thesis, University of Bremen, Bremen, Germany (in German).

Hibler, W. (1972), Removal of aircraft altitude variation from laser profiles of the Arctic ice pack, J. Geophys. Res., 77, 7190-7195, doi:10.1029/ JC077i036p07190.

Hoefle, B., M. Vetter, N. Pfeifer, G. Mandlburger, and J. Stoetter (2009), Water surface mapping from airborne laser scanning using signal intensity and elevation data, Earth Surf. Proc. Landforms, 34, 1635-1649.

Holland, M. M., C. M. Bitz, E. C. Hunke, W. H. Lipscomb, and J. L. Schramm (2006), Influence of the sea ice thickness distribution on polar climate in CCSM3, J. Clim., 19, 2398-2414.

Inoue, J., J. A. Curry, and J. A. Maslanik (2008), Application of Aerosondes to melt-pond observations over Arctic Sea ice, J. Atmos. Ocean. Tech., 25, 327-334.

Kay, J., T. L'Ecuyer, A. Gettelman, G. Stephens, and C. O’Dell (2008), The contribution of cloud and radiation anomalies to the 2007 arctic sea ice extent minimum, Geophys. Res. Lett., 35, L08503, doi:10.1029/ 2008 GL033451.

Kovacs, A., and J. Holladay (1990), Sea-ice thickness measurement using a small airborne electromagnetic sounding system, Geophysics, 55, 13271337.

Kovacs, A., J. Holladay, and C. Bergeron (1995), The footprint altitude ratio for helicopter electromagnetic sounding of sea-ice thickness: Comparison of theoretical and field estimates, Geophysics, 60, 374-380.

Kwok, R., G. F. Cunningham, M. Wensnahan, I. Rigor, H. J. Zwally, and D. Yi (2009), Thinning and volume loss of the Arctic Ocean sea ice cover: 2003-2008, J. Geophys. Res., 114, C07005, doi:10.1029/ 2009JC005312.

Lieser, J. (2005), Sea ice conditions in the northern North Atlantic in 2003 and 2004. Observations during RV POLARSTERN cruises ARKTIS XIX/1a and b and ARKTIS XX/2, Rep. Polar Res., 504, 197 pp., Available at http://hdl.handle.net/10013/epic.10509.

Maslanik, J., S. Drobot, C. Fowler, W. Emery, and R. Barry (2007a), On the Arctic climate paradox and the continuing role of atmospheric circulation in affecting sea ice conditions, Geophys. Res. Lett., 34, L03711, doi:10.1029/2006GL028269.
Maslanik, J. A., C. Fowler, J. Stroeve, S. Drobot, J. Zwally, D. Yi, and W. Emery (2007b), A younger, thinner Arctic ice cover: Increased potential for rapid, extensive sea-ice loss, Geophys. Res. Lett., 34, L24501, doi:10.1029/2007GL032043.

McLaren, A. J., et al. (2006), Evaluation of the sea ice simulation in a new coupled atmosphere-ocean climate model (HadGEM1), J. Geophys. Res., 111. C12014, doi:10.1029/2005JC003033.

Meehl, G., et al. (2006), Climate change projections for the twenty-first century and climate change commitment in the CCSM3, J. Clim., 19, 2597-2616.

Nghiem, S. V., I. G. Rigor, D. K. Perovich, P. Clemente-Colon, J. W. Weatherly, and G. Neumann (2007), Rapid reduction of Arctic perennial sea ice, Geophys. Res. Lett., 34, L19504, doi:10.1029/2007GL031138.

Ogi, M., I. G. Rigor, M. G. McPhee, and J. M. Wallace (2008), Summer retreat of Arctic sea ice: Role of summer winds, Geophys. Res. Lett., 35, L24701, doi:10.1029/2008GL035672.

Parkinson, C. L., and D. J. Cavalieri (2008), Arctic sea ice variability and trends, 1979-2006, J. Geophys. Res., 113, C07003, doi:10.1029/ 2007JC004558.

Percival, D. B., D. A. Rothrock, A. S. Thorndike, and T. Gneiting (2008), The variance of mean sea-ice thickness: Effect of long-range dependence, J. Geophys. Res., 113, C01004, doi:10.1029/2007JC004391.

Perovich, D., T. Grenfell, J. Richter-Menge, B. Light, W. Tucker, and H. Eicken (2003), Thin and thinner: Sea ice mass balance measurements during SHEBA, J. Geophys. Res., 108 (C3), 8050, doi:10.1029/ 2001JC001079.

Perovich, D., S. Nghiem, T. Markus, and A. Schweiger (2007), Seasonal evolution and interannual variability of the local solar energy absorbed by the Arctic sea ice-ocean system, J. Geophys. Res., 112, C03005, doi:10.1029/2006JC003558.

Perovich, D. K., J. A. Richter-Menge, K. F. Jones, and B. Light (2008), Sunlight, water, and ice: Extreme Arctic sea ice melt during the summer of 2007, Geophys. Res. Lett., 35, L11501, doi:10.1029/2008GL034007.

Peterson, I. K., S. J. Prinsenberg, and J. S. Holladay (2008), Observations of sea ice thickness, surface roughness and ice motion in Amundsen Gulf, J. Geophys. Res., 113, C06016, doi:10.1029/2007JC004456.

Pfaffling, A., and J. E. Reid (2009), Sea ice as an evaluation target for HEM modelling and inversion, J. Appl. Geophys., 67, 242-249.

Pfaffling, A., C. Haas, and J. E. Reid (2007), Direct helicopter EM - Sea-ice thickness inversion assessed with synthetic and field data, Geophysics, 72 , F127-F137.

Prinsenberg, S., J. Holladay, and J. Lee (2002), Measuring ice thickness with eisflow ${ }^{T M}$, a fixed-mounted helicopter electromagnetic-laser system, 12th International Offshore and Polar Engineering Conference, Conference Proceedings, 1, 737-740.

Rampal, P., J. Weiss, and D. Marsan (2009), Positive trend in the mean speed and deformation rate of Arctic sea ice, 1979-2007, J. Geophys. Res., 114, C05013, doi:10.1029/2008JC005066.

Reid, J., A. Pfaffling, and J. Vrbancich (2006), Airborne electromagnetic footprints in 1D earths, Geophysics, 71, G63-G72.

Rothrock, D. A., D. B. Percival, and M. Wensnahan (2008), The decline in arctic sea-ice thickness: Separating the spatial, annual, and interannual variability in a quarter century of submarine data, J. Geophys. Res., 113, C05003, doi:10.1029/2007JC004252.

Schauer, U. (2008), The expedition ARKTIS-XXII/2 of the research vessel "Polarstern" in 2007, Rep. Polar Res., 579, 271 pp., Available at http:// hdl.handle.net/10013/epic.30947.

Steele, M., W. Ermold, and J. Zhang (2008), Arctic Ocean surface warming trends over the past 100 years, Geophys. Res. Lett., 35, L02614, doi:10.1029/2007GL031651.

Stroeve, J., M. M. Holland, W. Meier, T. Scambos, and M. Serreze (2007), Arctic sea ice decline: Faster than forecast, Geophys. Res. Lett., 34, L09501, doi:10.1029/2007GL029703.

Thiede, J. (2002), Polarstern Arktis XVII/2: Cruise Report: AMORE 2001 (Arctic Mid-Ocean Ridge Expedition, Rep. Polar Res., 421, 390 pp. Available at http://hdl.handle.net/10013/epic.10426.

Thorndike, A., D. Rothrock, G. Maykut, and R. Colony (1975), Thickness distribution of sea ice, J. Geophys. Res., 80,33, doi:10.1029/ JC080i033p04501.

Tucker, W., J. Weatherly, D. Eppler, L. Farmer, and D. Bentley (2001), Evidence for rapid thinning of sea ice in the western Arctic Ocean at the end of the 1980s, Geophys. Res. Lett., 28, 2851-2854, doi:10.1029/ 2001 GL012967.

Wadhams, P. (1997), Ice thickness in the Arctic Ocean: The statistical reliability of experimental data, J. Geophys. Res., 102, 27,951-27,959, doi:10.1029/97JC02503.

Wadhams, P. (2000a), Ice in the Ocean, Gordon and Breach Science Publishers, New York. 
Wadhams, P., and N. Davis (2000b), Further evidence of ice thinning in the Arctic Ocean, Geophys. Res. Lett., 27, 3973-3975, doi:10.1029/ 2000GL011802

Wadhams, P., and T. Davy (1986), On the spacing and draft distributions for pressure ridge keels, J. Geophys. Res., 91, 10,697-10,708, doi:10.1029/JC091iC09p10697.

Wadhams, P., and R. Horne (1980), An analysis of ice profiles obtained by submarine sonar in the Beaufort Sea, J. Glaciol., 25, 401-424.

Warren, S., I. Rigor, N. Untersteiner, V. Radionov, N. Bryazgin, Y. Aleksandrov, and R. Colony (1999), Snow depth on Arctic sea ice, J. Clim., 12, 1814-1829.

Winsor, P. (2001), Arctic sea ice thickness remained constant during the 1990s, Geophys. Res. Lett., 28, 1039-1041, doi:10.1029/2000GL012308.
Yu, Y., G. Maykut, and D. Rothrock (2004), Changes in the thickness distribution of Arctic sea ice between 1958-1970 and 1993-1997, J. Geophys. Res., 109, C08004, doi:10.1029/2003JC001982.

C. Haas, Department of Earth Sciences, University of Alberta, 1-26 ESB Edmonton, AB T6G 2E3, Canada.

S. Hendricks, Alfred Wegener Institute of Polar and Marine Research, Bussestr. 24, Bremerhaven, D-27570, Germany.

T. Martin, Leibniz Institute of Marine Sciences, IFM-GEOMAR, Duesternbrooker Weg 20, D-24105 Kiel, Germany.

A. Pfaffhuber, Norwegian Geotechnical Institute, PO Box 3930, Ullevål Stadion, N-0806 Oslo, Norway.

L. Rabenstein, Swiss Federal Institute of Technology, Institute of Geophysics, Sonneggstr. 5, CH-8092 Zurich, Switzerland. (lasse. rabenstein@awi.de) 